\title{
Review of malaria situation in Cameroon: technical viewpoint on challenges and prospects for disease elimination
}

Christophe Antonio-Nkondjio 1,3,5*, Cyrille Ndo ${ }^{2,3}$, Flobert Njiokou ${ }^{3,4}$, Jude D. Bigoga ${ }^{6,7}$, Parfait Awono-Ambene ${ }^{1}$, Josiane Etang ${ }^{1,2,8}$, Albert Same Ekobo ${ }^{4}$ and Charles S. Wondji,

\begin{abstract}
Malaria still has a devastating impact on public health and welfare in Cameroon. Despite the increasing number of studies conducted on disease prevalence, transmission patterns or treatment, there are to date, not enough studies summarising findings from previous works in order to identify gaps in knowledge and areas of interest where further evidence is needed to drive malaria elimination efforts. The present study seeks to address these gaps by providing a review of studies conducted so far on malaria in Cameroon since the 1940s to date. Over 250 scientific publications were consulted for this purpose. Although there has been increased scale-up of vector control interventions which significantly reduced the morbidity and mortality to malaria across the country from a prevalence of $41 \%$ of the population reporting at least one malaria case episode in 2000 to a prevalence of $24 \%$ in 2017, the situation is not yet under control. There is a high variability in disease endemicity between epidemiological settings with prevalence of Plasmodium parasitaemia varying from 7 to $85 \%$ in children aged 6 months to 15 years after long-lasting insecticidal nets (LLINs) scale-up. Four species of Plasmodium have been recorded across the country: Plasmodium falciparum, P. malariae, P. ovale and P. vivax. Several primate-infecting Plasmodium spp. are also circulating in Cameroon. A decline of artemisinin-based combinations therapeutic efficacy from 97\% in 2006 to 90\% in 2016 have been reported. Several mutations in the P. falciparum chloroquine resistance (Pfcrt) and P. falciparum multidrug resistance 1 (Pfmdr1) genes conferring resistance to either 4-amino-quinoleine, mefloquine, halofanthrine and quinine have been documented. Mutations in the Pfdhfr and Pfdhps genes involved in sulfadoxine-pyrimethamine are also on the rise. No mutation associated with artemisinin resistance has been recorded. Sixteen anopheline species contribute to malaria parasite transmission with six recognized as major vectors: An. gambiae, An. coluzzii, An. arabiensis, An. funestus, An. nili and An. moucheti. Studies conducted so far, indicated rapid expansion of DDT, pyrethroid and carbamate resistance in An. gambiae, An. coluzzii, An. arabiensis and An. funestus threatening the performance of LLINs. This review highlights the complex situation of malaria in Cameroon and the need to urgently implement and reinforce integrated control strategies in different epidemiological settings, as part of the substantial efforts to consolidate gains and advance towards malaria elimination in the country.
\end{abstract}

Keywords: Malaria, Plasmodium, Vector control, Drug resistance, Insecticide resistance, Anopheles, Cameroon

\footnotetext{
*Correspondence: antonio_nk@yahoo.fr

${ }^{1}$ Laboratoire de Recherche sur le Paludisme, Organisation de Coordination pour la lutte contre les Endémies en Afrique Centrale (OCEAC), B. P.288 Yaoundé, Cameroun

Full list of author information is available at the end of the article
} 


\section{Background}

Malaria is still an important public health threat in Cameroon with the whole country exposed to the risk of transmission $[1,2]$. Although significant progress has been made in the recent past, the disease remains prevalent with a high number of suspected cases in health care facilities varying between 3.3-3.7 million per year [1]. Malaria parasite transmission is highly heterogeneous with high and perennial parasite transmission occurring in the forest, coastal and humid savanna areas and low parasite transmission in highlands and seasonal parasite transmission in sahelian and dry savanna areas [3]. Plasmodium falciparum is the main parasite responsible for over $95 \%$ of the cases [4]. Other human-infecting Plasmodium species circulating in the country include P. malariae, P. ovale and $P$ vivax [5]. The latter parasite species which was thought to be absent from West and Central Africa in more recent evolutionary times, has now been reported in the country [6-8], highlighting the changing pattern of malaria in Cameroon. However, the epidemiological role of this species as well as local vector species competence for this parasite is still to be determined. Up to 52 anopheline species have been reported in the country so far, with 16 recognized as main or secondary vectors [9-11]. Six of the species are among the most efficient vectors in sub-Saharan Africa, namely, $A n$. gambiae (s.s.), An. coluzzii, An. arabiensis, An. funestus, An. nili and An. moucheti $[11,12]$.

Vector control has been a vital component of malaria prevention and control, relying mainly on the use of longlasting insecticidal nets (LLINs). Since 2000, Cameroon has benefited from the support of various international partners to implement malaria control interventions [9, 13]. Over 20 million LLINs have so far been freely distributed to the population through several campaigns [1], with the support of partners (e.g. the Global Fund). Although the coverage rate of the population is still below the target of the Ministry of Health ( $>80 \%$ of the households having one net for two persons), it is estimated that between 2000 and 2015, the scale-up of treated bednets across the country resulted in a significant decrease in the prevalence of malaria reported cases from $41 \%$ to $24.3 \%$, and $54 \%$ decrease in malaria related mortality (from about 13,000 to 6000 per year) [1].

In the northern regions of the country where malaria parasite transmission is seasonal and prone to frequent eruptions of epidemics, seasonal chemoprevention has been introduced and targets mostly children [1]. In 2017, Cameroon was selected as a US President's Malaria Initiative (PMI) focus country. The PMI programme, which will focus essentially in the North and Far North regions, will support the procurement of over 250,000 LLINs for routine distribution to pregnant women during antenatal care and will undertake indoor residual spraying (IRS) trials to foster malaria elimination in this part of the country [14]. A third nationwide free distribution of over 15 million LLINs to the population is planned for 2019 [1]. Other interventions are being piloted in other epidemiological settings of the country such as larviciding in the city of Yaoundé and the PADY (Projet d'Assainissement de Yaoundé) programme focusing on hygiene and sanitation in Yaoundé $[15,16]$. Concerning malaria treatment, several programmes including case management are undertaken regularly to improve the management of malaria cases and tracking of drug resistance [17-23]. All these efforts, if well-coordinated, could further improve malaria control in Cameroon. Thus, there is still a need to further probe into the understanding of malaria epidemiology and transmission ecology for informed decision-making and to better coordinate control intervention strategies across the country.

Although there have been several studies on malaria epidemiology, case management, parasite prevalence, drug resistance, vectors distribution, bionomics, role in malaria parasite transmission or insecticide resistance since the 1950s, little has been done to assess the impact of control interventions on disease transmission. Also, there are still not enough reviews summarising previous data in order to identify gaps in knowledge or to document recent evolution and dynamics of the vectors or the parasites. Such information is essential for the management of control programmes and scale-up of new or supplemental intervention strategies.

The objective of the present review is to collate information from previous studies in order to better appraise the complexity of malaria situation and evidence in order to guide efforts towards malaria elimination in Cameroon. Although strengthening the health care system is an important requirement to achieve malaria elimination this has not been included in the present review which limits itself to an assessment of technical challenges and interventions.

\section{Data retrieval}

Information on malaria in Cameroon were extracted from published reports. Online bibliographic databases including PubMed, Google and Google Scholar were used to search for information. Terms used to guide these searches included "malaria", "parasite", "drug resistance", "vector control", "Plasmodium", "LLINs", "insecticide resistance", "Anopheles", "Cameroon", "susceptibility", "case management" "Yaoundé" and "Douala". The search period included 1940 to 2019. The search resulted in 1029 articles. Over 750 papers were excluded because they were not on malaria or not reporting data from Cameroon.

Information extracted from each selected published study were entered into a Microsoft Excel spreadsheet 
for easy access and data analysis. Information registered included authors names, the year of the study, methods and main findings.

\section{Situation of malaria in Cameroon}

Cameroon is situated in central Africa, within the Gulf of Guinea at a latitude between $2-13^{\circ} \mathrm{N}$ and a longitude between $9-16^{\circ} \mathrm{E}$. It has a surface area of approximately $475,000 \mathrm{~km}^{2}$ with a population of about 24 million [24]. It is bordered to the West by Nigeria, to the North and East by Chad, to the East by Central African Republic and to the South by Congo, Gabon and Equatorial Guinea [25]. The country also has a coastal border of about $400 \mathrm{~km}$ with the Atlantic Ocean. Administratively, Cameroon is divided into 10 administrative regions covering different ecological domains (Fig. 1). Data from the demographic and health survey (DHS) and from the malaria indicator survey (MIS), indicated vegetation and altitude as important predictors of the geographical distribution of malaria in Cameroon [2]. During the last decade an increase in temperature of $0.4{ }^{\circ} \mathrm{C}$ and decrease in rainfall of $10-20 \%$ have been reported, compared to the period 1951-1980 [26]. Across sub-Saharan Africa, similar projections have been reported with an increase in temperature of $1.5^{\circ} \mathrm{C}$ above the $1951-1980$ baseline level [27]. Although this situation coincided with a certain number of events such as frequent reports of dengue cases in the country [28, 29], outbreaks of chikungunya and yellow fever in Cameroon and neighbouring countries [30-32] or invasion of Cameroon by Aedes albopictus mosquitoes originating from Asia [33, 34], there have not been many studies assessing the direct relationship between vectorborne diseases dynamics and changing climate conditions in Cameroon. This deserves further investigation in the light of some recent reviews [35-39].

The Far North region belongs to the sahelian domain characterized by hot and dry weather with annual rainfall never exceeding $700 \mathrm{~mm} /$ year. According to malaria stratification the Far North region belongs to a hyperendemic malaria stratum with seasonal malaria parasite transmission prone to cyclic outbreaks. The Far North region is one of the most densely populated regions in the country, with a population estimated at 3.9 million inhabitants occupying a surface area of $34,263 \mathrm{~km}^{2}$ (Table 1) [40]. The fast demographic growth of the area, deforestation and desertification, deeply affected the landscape of the area which is now witnessing extended dry seasons with a reduction in crops yields and livestock productivity [41].

In this region, frequent malaria epidemics occur during the rainy season which last $2-3$ months [42]. Surveys conducted before the implementation of LLINs in the sites of Koza, Yagoua and Maga, indicated the prevalence of $P$. falciparum parasitaemia in children $(n=924)$ aged between 2 and 9 years-old, varying from $8.5 \%$ at the end of the dry season to $40.8 \%$ during the rainy season $[43,44]$. A similar pattern was recorded in other sites of the region in Mahouda, Simatou, Guividig and Farahoulou with malaria prevalence varying from $10 \%(62 / 616)$ to $17.2 \%(109 / 632)$ [44]. Following LLINs scale-up, a decrease in the prevalence in children to $7.3-9.2 \%(n=341)$ was recorded in 2017 [45]. However, the region still reported the highest number of malaria cases in 2015 in the country according to the NMCP annual report [3]. Entomological inoculation rate (EIR) was not reported to vary much before and after LLINs scale-up it is estimated to range between 2.4-24.0 infective bites/person/month during the rainy season, with An. arabiensis as the main vector species $[46,47]$. The difference between reported entomological and epidemiological data may be due to the fact that the studies cited in the present review were not conducted in the same sites.

The North region is located within the dry savanna domain and is characterized by a rainy season lasting 3-5 months with annual rainfall reaching $1000 \mathrm{~mm} /$ year. According to malaria stratification, this area belongs to a hyperendemic malaria stratum with seasonal malaria parasite transmission prone to cyclic outbreaks (transmission period could be extended compare to the Far North region). The population in the area is estimated at 2.4 million inhabitants on a surface area of $66,090 \mathrm{~km}^{2}$. The region population more than doubled during the last decades due in part to migration of population affected by droughts or displaced by the Boko Haram insurgency. Before LLINs scale-up in the country, malaria parasite prevalence in children of $1-15$ years-old, was estimated to vary between $6.5-30.7 \%(n=655)$ during cross-sectional surveys in the health districts of Lagdo [46, 48]. The EIR was found to vary between 2.7-36.5 infected bites/person/month $[49,50]$. After LLINs scale-up, average malaria parasite prevalence levels of $30.4 \%$ [varying significantly from $28.6 \%(798 / 2795)$ for net users and $35 \%(243 / 694)$ for non-net users] was recorded in the health districts of Garoua, Pitoa and Mayo-Oulo in children of 6 months to 5 years-old (Table 2) [51]. Intense transmission was found to occur during the rainy season with estimates varying from 24.5 to 60 infective bites/ person/month in the health districts of Lagdo, Garoua, Pitoa, Mayo Mbocki and Mayo Oulo [49, 50, 52, 53]. The increase in the EIR rate recorded for this region could derive from the fact that entomological surveys were undertaken in different sites before and after LLINs scale-up. It is possible that localities scoring high EIR had much higher rate before LLINs scale-up. Main vectors species in the area are An. arabiensis, An. gambiae and An. funestus. Other species playing a role in malaria parasite transmission are An. pharoensis, An. coluzzii, An. rufipes and An. ziemanni [50,52]. 


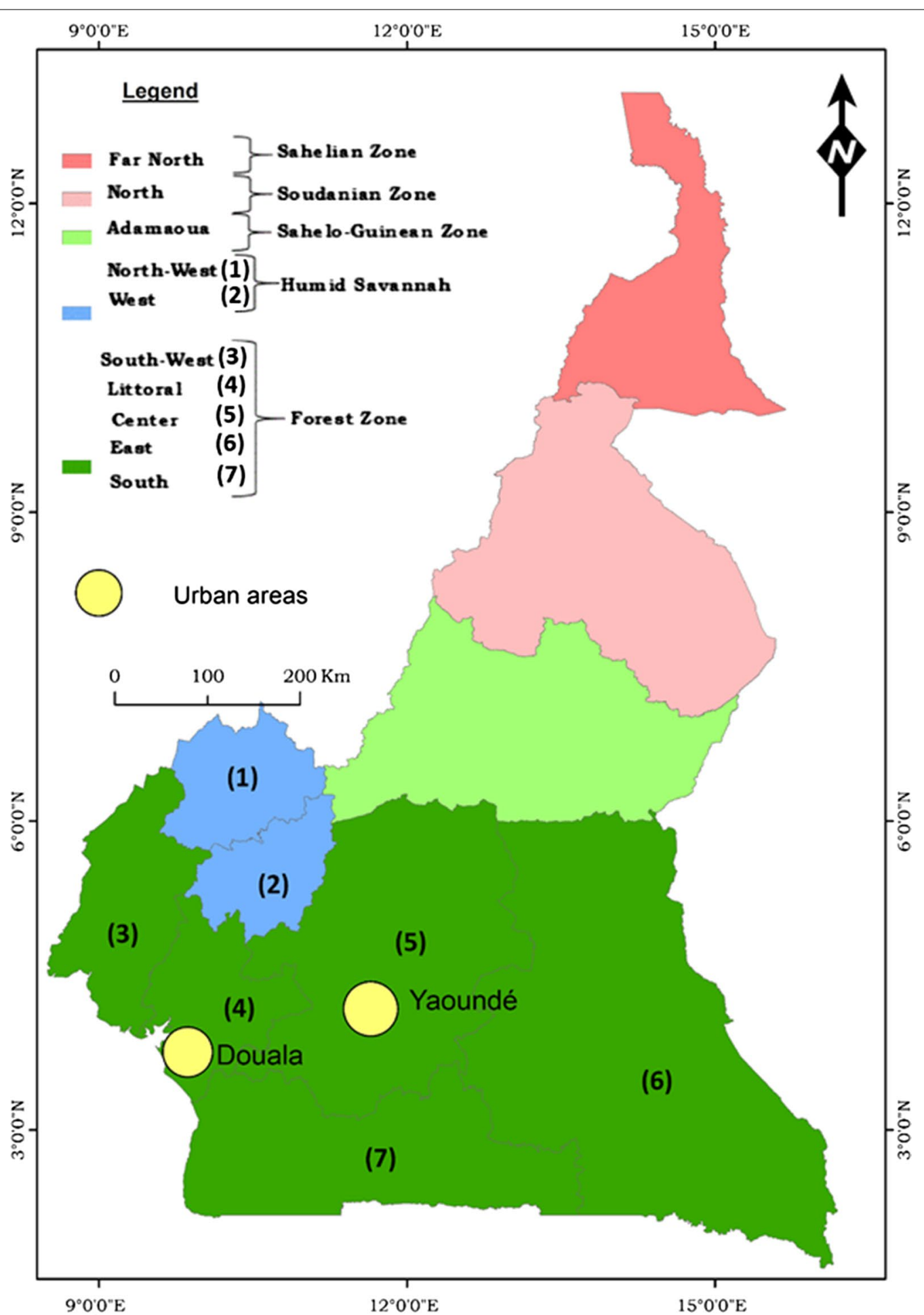

Fig. 1 A map of Cameroon showing climatic and administrative divisions 
Table 1 Population repartition and bed net coverage in the different regions of Cameroon

\begin{tabular}{|c|c|c|c|c|c|c|c|}
\hline Regions & Population in 1987 & Population in 2015 & Size $\left(\mathrm{km}^{2}\right)$ & Inhabitants $/ \mathrm{km}^{2}$ & $\begin{array}{l}\text { Bednet } \\
\text { coverage in } \\
2013^{\mathrm{a}}\end{array}$ & $\begin{array}{l}\text { Bednet } \\
\text { coverage in } \\
2017^{\mathrm{a}}\end{array}$ & $\begin{array}{l}\text { Bednet } \\
\text { usage in } \\
2017^{b}\end{array}$ \\
\hline Far North & $1,855,695$ & $3,945,168$ & 34,263 & 90.8 & 83.4 & 80.9 & 35.4 \\
\hline North & 832,165 & $2,410,936$ & 66,090 & 25.5 & 75.3 & 93.9 & 83.1 \\
\hline Adamaoua & 495,185 & $1,183,551$ & 63,701 & 13.9 & 70.9 & 81.8 & 80.1 \\
\hline North-West & $1,237,348$ & $1,950,667$ & 17,300 & 99.9 & 79.2 & 66.9 & 56.0 \\
\hline West & $1,339,791$ & $1,906,831$ & 13,892 & 123.8 & 45.0 & 74.0 & 57.3 \\
\hline Centre & $1,651,600$ & $4,098,592$ & 68,953 & 44.9 & 59.8 & 78.5 & 61.2 \\
\hline Littoral & $1,352,833$ & $3,309,558$ & 20,248 & 124.0 & 53.5 & 73.0 & 59.3 \\
\hline South & 373,798 & 745,198 & 47,191 & 13.4 & 68.7 & 83.7 & 54.3 \\
\hline South-West & 838,042 & $1,534,232$ & 25,410 & 51.8 & 67.1 & 69.7 & 59.1 \\
\hline East & 517,198 & 832,869 & 109,002 & 7.1 & 58.6 & 77.2 & 55.6 \\
\hline Cameroon & $10,493,655$ & $21,917,602$ & 475,000 & 46.14 & 65.6 & 76.6 & 58.3 \\
\hline
\end{tabular}

a Proportion of households with at least one LLIN

b The proportion of people who slept in a LLIN the previous night

Table 2 Summary of entomological and epidemiological data according to regions before and after LLINs scale-up

\begin{tabular}{|c|c|c|c|c|c|c|c|}
\hline \multirow[t]{2}{*}{ Region } & \multicolumn{2}{|c|}{ Before LLINs scale-up } & \multicolumn{2}{|c|}{ After LLINs scale-up } & \multirow{2}{*}{$\begin{array}{l}\text { Transmission } \\
\text { pattern }\end{array}$} & \multirow[t]{2}{*}{ Main vector } & \multirow[t]{2}{*}{ References } \\
\hline & $E I R$ & $\begin{array}{l}\text { Epidemiological } \\
\text { data (\%) }\end{array}$ & $E I R$ & $\begin{array}{l}\text { Epidemiological } \\
\text { data }^{b}(\%)\end{array}$ & & & \\
\hline Far North & $6.0-20.0 \mathrm{ib} / \mathrm{p} / \mathrm{m}$ & $8.5-40.8^{b}$ & $6.0-20.0 \mathrm{ib} / \mathrm{p} / \mathrm{m}$ & $7.3-9.2^{b}$ & Seasonal & An. arabiensis & {$[42-47]$} \\
\hline North & $2.7-36.5 \mathrm{ib} / \mathrm{p} / \mathrm{m}$ & $6.5-30.7^{\mathrm{a}}$ & $24.5-60.0 \mathrm{ib} / \mathrm{p} / \mathrm{m}$ & $28.6-35^{c}$ & Seasonal & $\begin{array}{l}\text { An. arabiensis; An. } \\
\text { gambiae (s.s.); } \\
\text { An. funestus }\end{array}$ & {$[46,49-53]$} \\
\hline Adamaoua & $100 \mathrm{ib} / \mathrm{p} / \mathrm{yr}$ & $17.5^{\mathrm{b}}$ & & $8.1-10.6^{b}$ & $\begin{array}{l}\text { Perennial with } \\
\text { high intensity }\end{array}$ & $\begin{array}{l}\text { An. gambiae (s.s.); } \\
\text { An. coluzzii; An. } \\
\text { funestus }\end{array}$ & [55-59] \\
\hline $\begin{array}{l}\text { North-West and } \\
\text { West }\end{array}$ & $62.8-90.5 \mathrm{ib} / \mathrm{p} / \mathrm{yr}$ & $25.0-53.2^{\mathrm{a}}$ & $2.2-11.0 \mathrm{ib} / \mathrm{p} / \mathrm{yr}$ & $9.3-22.4^{a}$ & $\begin{array}{l}\text { Perennial with } \\
\text { low intensity }\end{array}$ & $\begin{array}{l}\text { An. Gambiae (s.s.); } \\
\text { An. funestus }\end{array}$ & {$[8,58,60-64]$} \\
\hline $\begin{array}{l}\text { Littoral, South- } \\
\text { West, Centre, } \\
\text { South and East }\end{array}$ & $\begin{array}{l}149.0-287.0 \\
\mathrm{ib} / \mathrm{p} / \mathrm{yr}\end{array}$ & $35.0-85.4^{\mathrm{a}}$ & $0.7-1.4 \mathrm{ib} / \mathrm{p} / \mathrm{m}$ & $9.0-56.2^{a}$ & $\begin{array}{l}\text { Perennial with } \\
\text { high intensity }\end{array}$ & $\begin{array}{l}\text { An. gambiae (s.s.); } \\
\text { An. coluzzii; } \\
\text { An. funestus; } \\
\text { An. moucheti; } \\
\text { An. nili }\end{array}$ & $\begin{array}{c}{[18,44,49,58} \\
64-95]\end{array}$ \\
\hline $\begin{array}{l}\text { Yaoundé and } \\
\text { Douala }\end{array}$ & $3.0-33.0 \mathrm{ib} / \mathrm{p} / \mathrm{yr}$ & $35.0^{\mathrm{a}}$ & 0-90.0 ib/p/yr & $35.0^{\mathrm{b}}$ & Seasonal & $\begin{array}{l}\text { An. gambiae (s.s.); } \\
\text { An. coluzzii }\end{array}$ & {$[66,96-103]$} \\
\hline
\end{tabular}

a Prevalence of malaria parasite in asymptomatic children of 1 to 15 years

b Prevalence of malaria parasite in asymptomatic children of 2 to 9 years

c Prevalence of malaria parasite in asymptomatic children of 6 months to 5 years-old

Abbreviations: EIR, entomological inoculation rate; ib/p/m, infected bites per person per month; ib/p/yr, infected bites per person per year

The Adamaoua region situated mid-way between the North and the Centre regions, is dominated by a landscape above $1000 \mathrm{~m}$ and is characterized by humid savannah with one rainy season lasting over 6 months with a moderate climate and precipitation which amounts to $1500 \mathrm{~mm} /$ year. In some parts of the region, daily average temperatures could be as low as $20^{\circ} \mathrm{C}$ part of the year. The region could be classified as belonging to a mesoendemic stratum with perennial malaria parasite transmission due to the abundance of rivers and lakes. The population of the area is about 1.18 million inhabitants living on a surface area of $63,701 \mathrm{~km}^{2}$ [40]. The region as well as the North, Far-North and East regions have several displaced camps for refugees or displaced persons coming from neighbouring countries, such as, Nigeria, Chad or the Central African Republic [54]. Yet there is still not enough information on how this influx of people has influenced local disease epidemiology which 
still deserves further investigation. Before LLINs, scaleup malaria parasite prevalence in 2-9 year-old children was $17.5 \%(n=724)$ [55] and entomological inoculation rate (EIR) was 100 infected bites/person/year [56, 57]. After LLINs scale-up in 2017, parasites rates in febrile children of 2-9 years-old were reported to vary from 8.1 to $10.6 \%(n=315)$ [58]. High Plasmodium infections in mosquitoes varying from 5 to $20 \%$ were recorded in $A n$. funestus and An. gambiae [59].

The West and North-West regions are all situated in highland areas (> $1000 \mathrm{~m}$ above sea level) and characterized by a temperate climate with rainfall lasting up to 8 months and a vegetation dominated by grasslands. These areas are considered as hypoendemic with seasonal malaria parasite transmission occurring at very low level. Average annual rainfall is estimated at $1800 \mathrm{~mm} /$ year. The West and North-West region has each over 1.9 million inhabitants. The West region covers a surface area of $13,892 \mathrm{~km}^{2}$ whereas the North-West covers a surface area of $17,300 \mathrm{~km}^{2}$. A survey conducted in the 1990 s before the scale-up of LLINs in these settings, indicated parasite prevalence reaching up to $25 \%$ in children of less than 15 years-old $(n=530)[44,60]$. Entomological inoculation rate in the West region was found to vary from 62.8 to 90.5 infective bites/person/year [61]. After LLINs scaleup, a parasite rate varying from 9.3 to $22.4 \%(n=173)$ in febrile children of 2-15 years-old was reported in different health care units of the West region $[8,58]$. Retrospective analysis conducted between 2006 and 2012, in the health care district of Mbakong (North-West), showed a decrease in the parasite rate in febrile patients from $53.2 \%$ to $18.2 \%(n=4230)$ following LLINs scaleup and a usage rate of $>50 \%$ [62]. Current entomological investigations reported parasite inoculation rates varying from 4.9 to 11 infective bites/person/year in the highland areas of the North-West region [63], whereas 2.24 infective bites/person/month was recorded in the West region (Table 2) [61, 64]. Main vectors in the area are An. gambiae, An. coluzzii and An. funestus.

The Littoral, Centre, South-West, East and South regions all belong to the forest domain. This domain extends from the Atlantic coast to the border with the Central African Republic and is characterized by a succession of vegetation, including mangrove, deep equatorial evergreen forest and humid savannah. The climate comprises four seasons, two rainy seasons and two dry seasons with annual rainfall varying between $1500 \mathrm{~mm} /$ year inland to $4000 \mathrm{~mm} /$ year on the sea coast. These regions are considered as belonging to a holoendemic stratum with high and perennial malaria parasite transmission. The Littoral, Centre and South-West regions are the most densely populated, with the population varying from 4.09 million for the Centre, 3.3 million for the
Littoral and 1.5 million inhabitants for the South-West region. The East and South regions are the less densely populated with a population of 745,000 inhabitants in the South and 832,000 inhabitants in the East region (Table 1). Prior to LLINs scale-up, the prevalence rate in children aged 6 months to 15 years-old ranged from 35 to $85.4 \%$ ( $n=109-1690)[44,65-69]$. Studies conducted in the South-West region after LLINs mass campaigns scale-up, on children aged one month to 14 years-old, indicated a prevalence varying from 9 to $41.5 \%(n=454)$ during the rainy season in Tiko, Limbé, Idenau, Mutengene and Buéa [18, 68, 70-75]. High parasite prevalence varying from 41.7 to $56.2 \%(n=828)$ along the slope of Mount Cameroon was also recorded [76, 77]. The social crisis affecting the North-West and South-West regions of the country with a displaced population, could be affecting malaria epidemiology in the area and this could constitute an enormous challenge that could impede malaria elimination or control efforts in these regions and neighbouring regions. In the South and Centre regions a decrease in malaria parasite prevalence was recorded in the majority of settings with estimates of $6.6-29.5 \%(n=2525)[58,78,79]$. However, high parasite prevalence estimates were still recorded in some places such as Nkolbisson (43.4\%) $(n=315)$ and Mfou (77.2\%) $(n=263)$ [80, 81]. In the Littoral region, malaria parasite prevalence ranged between $20.4-29.4 \%(n=288)$ [58, 71]. Regarding malaria parasite transmission, different patterns of transmission were reported. Before the scaleup of vector control tools, in the coastal cities of Tiko, Limbé and Ideanu, transmission estimates varied from 149 to 287 infective bites/person/year and this was similar to transmission level in the forested or highland areas (161 infective bites/person/year) [82]. Decreases in the transmission level was recorded following the scale-up of LLINs with transmission estimates as low as 0.7 infective bites/person/month in Tiko, 1.4 infective bites/person/ month in Mamfe [64]. In the Littoral, Centre and South regions, transmission was reported to vary between 100 and 350 infective bites/person/year before the scale-up of LLINs [49, 83-91]. After scale-up, EIR values ranging from 0 to 100 infective bites/person/year [92-95] were reported (Table 2).

Because of the poor road state in the East region, there have not been many studies conducted in this part of the country. Yet this region is considered as one of the most affected by malaria in the country [1]. This region is also one of the most vulnerable in the country because of its proximity with the Central African Republic and receives regularly influx of population running the social crisis in Central African Republic. Because the East region could constitute a reservoir for malaria dissemination in Cameroon, it is urgent that more efforts to improve 
the treatment and disease prevention be undertaken to reduce the high endemicity of malaria in the area.

The cities of Yaoundé and Douala with a population of about 3 million inhabitants each [96] are similar to most of sub-Saharan cities $[97,98]$. They are characterised by a rapid demographic growth, unplanned urbanization, fast development of informal settlements, large-scale practice of urban agriculture and rapid evolution of insecticide resistance in vectors [96, 99-101], which all probably affect the dynamics and epidemiology of vector-borne diseases. Before LLINs scale-up, EIR varied between 0-33 infected bites/person/year. Parasite prevalence was reported at $35 \%(n=965)$ in children of $0-15$ years-old [66]. The parasite rate in febrile children of less than 15 years-old admitted in hospital was equal to $42.9 \%$ ( $n=$ 415) [102]. After LLINs scale-up, EIR levels of 0 to 90 infective bites/person/year and a prevalence of $35 \%$ in children aged 3-14 years-old in the general population $(n$ $=236$ ) were recorded $[101,103]$.

\section{Plasmodium species}

All four human Plasmodium species have been documented in Cameroon, including $P$ falciparum, $P$. ovle, $P$. malariae and $P$. vivax $[6,8,9]$. Plasmodium falciparum is by far the predominant species recorded in up to $95 \%$ of all infection cases [104, 105]. Plasmodium malariae and $P$. ovale represent each 1 and $3 \%$ of infection cases, respectively [9]. However, the distribution of the different Plasmodium species across the country could be underestimated as suggested by recent studies using molecular tools which indicated P. malariae infection cases in $17 \%$ out of 236 blood samples analysed [95, 106]. The study suggested the need to associate molecular tools in diagnostics to improve species detection. Genetic structure studies of $P$. falciparum suggested high diversity of circulating strains in Cameroon $[107,108]$.

Plasmodium vivax was recently reported from Cameroon [6-8]. Studies conducted so far suggested frequent occurrence of this parasite in Duffy-negative people in different epidemiological settings [6-8]. In the city of Dschang (West Cameroon), out of 484 blood samples collected consecutively from febrile outpatients attending the main hospital during a 3-month period, $P$. vivax infection was detected by PCR in 5.6\% (27/484) patients, representing 38.6\% (27/70) of all Plasmodium infection cases detected [8]. Another study conducted in Bolifamba (South-West Cameroon) indicated that 14.9\% (13/87) of Plasmodium infection cases were caused either exclusively or concomitantly by $P$. vivax, in individuals both positive (50\%) and negative (50\%) for the Duffy receptor [6]. In a larger study conducted in five locations in the South region of Cameroon, out of 201 malaria positive cases detected, six $P$. vivax and two mixed parasite infections ( $P$. falciparum $+P$. vivax), were detected corresponding to a prevalence of 4\% [7]. Yet the true profile of species occurrence and distribution across the country is not well documented. It is possible that $P$. vivax could have been misdiagnosed as $P$. ovale in the past since distinction in routine microscopy is very difficult. In neighbouring Equatorial Guinea, cases of $P$ vivax infection are also highly prevalent $[109,110]$. It is thought that the influx of workers from countries where $P$. vivax is endemic (Indonesia, Philippines) following the discovery of oil reserves in Equatorial Guinea could have increased P. vivax reservoir and transmission [110]. It is not clear whether subsequent expansion of the parasite in Cameroon could have resulted from population migration between the two countries. The discovery of $P$. vivax in Cameroon offers new research avenues on this species distribution, pathogenicity, genetic variability, transmission by different vectors species, interaction with other Plasmodium species and distribution in regard to urbanisation, climatic changes or malaria treatment policy. The expansion of $P$. vivax in Cameroon could oppose important challenges for malaria elimination in the country. One of these challenges could be the adoption of primaquine for radical cure of $P$. vivax related cases. Plasmodium vivax infections differ from other Plasmodium species because the parasites can lie dormant in a person's liver, and reawaken suddenly later to cause relapses of malaria. Primaquine is thus taken daily for 14 days to clear $P$. vivax parasites in the blood and liver to prevent subsequent relapses. However, this drug is considered to be associated to serious adverse effects (destruction of red blood cells), particularly for patients with hereditary deficiency of the enzyme glucose-6-phosphate dehydrogenase (G6PD) [111-113] and might require specific case management strategies. Another challenge is the proper diagnostic and procurement of new RDT tests for the detection of $P$. vivax infections in patients.

Great apes in Cameroon were also reported to harbour several Plasmodium species close to $P$. falciparum, $P$. vivax, $P$. malariae and $P$. ovale [114-116]. Six Plasmodium species closely related to human-infecting $P$. falciparum were reported in the central African equatorial forest region. These include $P$. reichnowi, $P$. gaboni and $P$. billcollinsi found in chimpanzees, and $P$. adleri, $P$. blacklocki and P. praefalciparum found in gorillas [117]. Anopheline species such as An. moucheti was considered to be a possible bridge vector between human and apes [118]. Plasmodium falciparum-like parasites infecting wild apes in southern Cameroon were not found to represent a recurrent source for human malaria [106]. In Malaysia, Southeast Asia, recurrent cases of human infections by Plasmodium knowlesi, an Asian simian malaria parasite, were regularly reported [119]. Although 
subsequent malaria control interventions induced a marked reduction in the incidence of $P$. falciparum and $P$. vivax malaria cases, an increase in the incidence of malaria cases from the simian parasite $P$. knowlesi was still recorded [120-123]. Given the potential for simian Plasmodium to be transmitted from human to human and the public health implications of this zoonosis, it becomes important that more surveillance activities be conducted on this end through frequent diagnostic of simian Plasmodium in blood donors or resident living close to primates in the forest regions. It is still not known whether primates could represent a reservoir for human-infecting Plasmodium. Moreover, in the context of malaria elimination, identifying sources for reinfection of mosquitoes or possibilities of parasite introgression could have implications for the successful implementation of vector control programmes.

\section{Malaria treatment and case management}

Following expansion of drug resistance, drug policy for malaria treatment in Cameroon gradually changed over the years from monotherapies with chloroquine and amodiaquine used as a first-line treatment for uncomplicated malaria to combination therapy [124]. Chloroquine was largely used from the 1970s through to 2002 [9]. From 1999 to 2004, following the adoption of an interim drug policy, amodiaquine was incorporated alongside chloroquine as an alternative first-line drug for uncomplicated malaria while sulfadoxine-pyrimethamine was used as a second line drug $[9,124]$. In 2004, following recurrent treatment failure to amodiaquine and sulfadoxine-pyrimethamine, the Ministry of Health of Cameroon reconsidered its policy and shifted to artemisinin-based combination therapy (ACT) used as a first-line treatment for uncomplicated malaria. Common ACT used in the country include artesunate-lumefanthrine, artesunateatovaquone-proguanyl, artesunate-amodiaquine, artesunate-mefloquine. Sulfadoxine-pyrimethamine is still recommended as an intermittent preventive treatment for malaria during pregnancy (IPTp) whereas injectable artemether or quinine are used in case of treatment failure or for severe malaria cases [9]. In the northern part of the country exposed to recurrent malaria outbreaks during the rainy season, the government introduced in 2016 seasonal malaria chemoprevention for children below 5 years-old $[1,14]$. The combination artesunate-amodiaquine (ASAQ) which was used before for the treatment of uncomplicated malaria cases for children under 5 years-old was replaced by artemether-lumefantrine (AL) provided free of charge to all families for malaria prevention. This strategy permitted to take in charge over $80 \%$ of children in the target settings in the North and FarNorth regions [1].
Case management in Cameroon includes: diagnosis of suspected cases; treatment of confirmed cases at health facilities and community level; scale-up of integrated community case management; pharmacovigilance and supply chain strengthening. Since 2011 the Cameroon government adopted free treatment of uncomplicated malaria for children of less than five years-old [1, 14]. Malaria diagnosis in most health care units is done through microscopic and/or TDR [1, 14, 20]. Since 2014 treatment of severe malaria is also free for children under 5 years-old $[1,14]$. Integrated community case management (iCCM) for diarrhoea, pneumonia and malaria using community health workers, was introduced in 2009 to target groups with difficult access to health care services [125]. ICCM include clinical diagnosis and treatment provided by trained and supervised community health workers (CHWs). The results of pilot programmes conducted in the East region of Cameroon (Doume and Nguelemendouka) with 456 trained community health workers indicated that this approach improve equitable access to treatment for malaria and diarrhoea in remote settings of Cameroon [125]. The implementation of modified iCCM programme with proactive screening of children of $<5$ years-old in high malaria transmission settings (Bare Bakem in the Littoral region) showed that it could increase the likelihood to find malaria parasite infections in children by $>67 \%$ [126]. In different settings where iCCM have been introduced it is reported to have increased the treatment rate for malaria, care seeking behaviour for fever, and has reduced the burden on health care facilities [127]. Yet this approach faces several challenges such as underutilisation or the attrition of trained CHWs, inadequate supervision and motivation of CHWs, prolonged and frequent unavailability of commodities for malaria diagnosis and treatment [126]. Concerning pharmacovigilance several studies have so far been conducted across the country to assess malaria drug efficacy. The efficacy and safety of artemisinin base combination have been evaluated in four sentinel sites, Garoua, Bamenda, Nkongsamba and Ebolowa [128, 129]. Also, eight generic artemisinin base combinations have been evaluated from 2005 to 2016 [24, 103, 124, 129, 130]. All these studies concluded to the continuous efficacy of artemisinin base combination in Cameroon [128, 129, 131]. For diagnostic and treatment of malaria cases, several programmes have been conducted across the country in order to strengthen health care workers practices [132-134]. Additional case management programmes conducted include seasonal malaria chemoprevention in the North and Far-North regions.

In order to achieve disease elimination, proper detection and treatment of malaria cases is required and the contribution of case management could become even 
more determinant, particularly in settings selected for malaria elimination, where the objective will be to track all cases to avoid reintroduction of malaria infected patients in malaria free zones.

\section{Drug resistance}

Current therapeutic efficacy studies suggest continuous efficacy of artemisinin-based combinations (with complete parasite clearance on day 3 ) in the country despite slight decline from $97 \%$ in 2006 to $90.2 \%$ in 2016 for artesunate-amodiaquine (AS-AQ), a compound largely used for malaria treatment in Cameroon [14]. Although these values are still largely in favour of a high efficacy of this combination there is a need to remain vigilant to avoid rapid expansion of drug resistance which could threaten the successful elimination of malaria. Yet if AS-AQ continues to be used as the official first-line treatment, then a policy change would need to be considered in the years to come. Fortunately, the Ministry of Health has started adopting artemether-lumefantrine as a firstline treatment in some part of the country [1, 14]. In Cameroon as in most countries in sub-Saharan Africa, almost half of drugs sold on the market or in some private health care units are fake and counterfeit medication of low quality [135]. Over $50 \%$ of the population get recourse to these drugs for their treatment [136, 137]. It is considered that substandard or fake antimalarials cause the death of 64,000 to 158,000 people in Africa in the recent years [138]. Controlling the quality of drugs sold on the market for improved case management constitute an important requirement to further consider in the perspective of malaria elimination.

Drug efficacy has been reported to be affected by mutations occurring in the Pfcrt and Pfmdr1 gene in P. falciparum [139-142]. Mutations in the Pfcrt gene in $P$. falciparum are known to be associated with chloroquine and amodiaquine resistance [140, 143], whereas mutations in the $P$. falciparum multidrug resistance 1 (Pfmdr1) are considered to confer resistance to a large set of compounds including chloroquine, mefloquine, halofanthrine and quinine [142, 144, 145]. Pfdhfr and Pfdhps alleles are considered to mediate resistance to sulfadoxine-pyrimethamine [146, 147]. Studies conducted between 2005 and 2009 indicated a high prevalence of Pfcrt $76 \mathrm{~T}$ mutation in various sites across Cameroon $[148,149]$. The Pfmdr1 86Y mutation was also recorded at high frequency [150] however, no mutations in the Pfcrt 72 and no duplication of the Pfmdr1 gene were detected $[149,151,152]$. A recent study assessing the evolution of resistance genes in P. falciparum in the SouthWest region of Cameroon in blood samples collected between 2003 and 2013, indicated rapid elimination of alleles conferring resistance to 4-aminoquinoline (chloroquine and amodiaquine) Pfcrt 76T, Pfmdr1, 86Y, 184F and $1246 \mathrm{Y}$ and return to chloroquine sensitive genotypes since the withdrawal of chloroquine [20,153]. However different evolutionary patterns of mutations associated with Pfcrt gene have been reported across the country, with novel mutations still reported from different settings, notably the Centre and South regions [148, 154]. For $p f d h f r / p f d h p s$ genes, no reduction in SNPs associated with antifolate drug resistance was recorded [20]. A study on pregnant women in the city of Yaoundé confirmed the presence of an increasing number of mutations on the Pfdhfr/Pfdhps genes [147]. Apinjoh et al. [72], described the presence of triple mutants on the Pfdhfr, Pfcrt, Pfdhps and Pfmdr1 genes in the South-West region (Table 3). The increase in the prevalence of mutations could result from intense selective pressure still going on with the use of sulfadoxine-pyrimethamine for chemoprophylaxis by pregnant women and other vulnerable groups. For the Pfkelch 13 gene few random mutations have been recorded. However, none of the mutations associated with artemisinin resistance in Southeast Asia have so

Table 3 Most prevalent drug resistant mutations in Plasmodium falciparum reported during recent years across Cameroon

\begin{tabular}{|c|c|c|c|c|}
\hline Gene & $\begin{array}{l}\text { Drugs affected } \\
\text { by gene } \\
\text { mutations }\end{array}$ & Mutations detected in Cameroon & Sites reporting drug resistance & References \\
\hline pfcrt & $C Q, A Q, L M$ & K76T, M74I, N75E, K76 T, Q271K, I356K & $\begin{array}{l}\text { Mutengene, Ebolowa, Yaoundé, Bertoua, Douala, } \\
\text { Kyé-Ossi, Ngaoundéré, Garoua }\end{array}$ & {$[7,17,20,147-149]$} \\
\hline pfdhfr & $\mathrm{SP}$ & N511, C59R, S108N & Yaoundé, Mont-Cameroon, Ngaoundéré, Garoua & {$[17,20,147-149]$} \\
\hline pfdhps & SP & $\begin{array}{l}\text { K142N, I431V, S436A, A581G, A613S, K540E, } \\
\text { A437G }\end{array}$ & Yaoundé, Mont-Cameroon, Mutengene, Garoua & {$[17,20,147,149]$} \\
\hline pfmdr-1 & $A Q, C Q, L M, M Q$ & N86Y, Y184F, D1246Y & Mutengene, Yaoundé, Garoua & {$[17,20,149]$} \\
\hline pfkelch13 & Artemisinine & $\mathrm{K} 189 \mathrm{~T}^{\mathrm{a}}$ & Mont-Cameroon & [17] \\
\hline
\end{tabular}

a This mutation does not confer resistance to artemisinine

Abbreviations: pfdhfr, P. falciparum dihydrofolate reductase; pfdhps, P. falciparum dihydropteroate synthase; pfcrt, P. falciparum chloroquine resistance transporter; pfmdr-1, P. falciparum multidrug resistance transporter 1; CQ, chloroquine; $A Q$, amodiaquine; LM, lumefantrine; SP, sulfadoxine-pyrimethamine; MQ, mefloquine 
far been recorded $[72,155,156]$. Yet Cameroon remains extremely vulnerable to potential risk of introduction and spread of artemisinin resistant mutations originating from Southeast Asia with the United Nation peace keeping operations with soldiers from Asia (Bangladesh and Pakistan troops) in Central African Republic [157] or oils workers from Asia in the neighbouring Equatorial Guinea [110]. The following stresses the need for regular surveillance activities to avoid the rapid spreading of these new mutations in Cameroon and the sub-region. It should also be important to conduct regular monitoring of the therapeutic efficacy of artemether-lumefantrine now widely used across the country.

\section{Vectors species distribution, bionomics and genetic variability}

Cameroon has one of the most diverse anopheline fauna in Africa with more than 50 species reported [10]. Sixteen of the species are recognised as main or secondary malaria vectors and are involved in malaria parasite transmission either permanently or occasionally [11, 53, 63]. Species considered as main malaria vectors include: An. gambiae (s.s.), An. coluzzii, An. arabiensis, An. funestus, An. nili and An. moucheti (Table 2). Recent progress in molecular biology and genomics has allowed in-depth studies on species distribution, bionomics, genetic variability and geographical distribution across the country. The distribution of these species is now well documented in favour of intensive field studies undertaken across the country [11, 158-161]. Secondary malaria vectors include species which are involved in malaria parasite transmission either occasionally or temporally. Up to 11 species have been classified in this group which comprises: $A n$. ovengensis, An. paludis, An. ziemanni, An. coustani, An. pharoensis, An. marshallii, An. rufipes, An. carnevalei, An. hancocki, An. leesoni and An. wellcomei [11, 52, 53, 63] (Table 4).

Table 4 Characteristics of species groups involved in malaria parasite transmission in Cameroon

\begin{tabular}{|c|c|c|c|c|c|c|}
\hline $\begin{array}{l}\text { Species complex/ } \\
\text { group }\end{array}$ & $\begin{array}{l}\text { No. of } \\
\text { species in } \\
\text { the group }\end{array}$ & Present in Cameroon & Resting behaviour & Feeding behaviour & $\begin{array}{l}\text { Role in malaria } \\
\text { parasite transmission } \\
\text { in Cameroon }\end{array}$ & $\begin{array}{l}\text { Geographical } \\
\text { distribution }\end{array}$ \\
\hline \multirow{4}{*}{$\begin{array}{l}\text { An. gambiae com- } \\
\text { plex }\end{array}$} & \multirow[t]{4}{*}{9} & An. gambiae & Endo/exophilic & Anthropophilic & High & Countrywide \\
\hline & & An. coluzzii & Endo/exophilic & Anthropophilic & High & Countrywide \\
\hline & & An. arabiensis & Exophilic & Anthropozoophilic & High & Sahelian and savannah \\
\hline & & An. melas & Exophilic & Anthropophilic & Unknown & Coastal \\
\hline \multirow[t]{4}{*}{ An. funestus group } & \multirow[t]{4}{*}{11} & An. funestus & endophilic & Anthropophilic & High & Countrywide \\
\hline & & An. leesoni & Exophilic & Anthropophilic & Minor & Countrywide \\
\hline & & An. rivulorum & Exophilic & Zoophilic & Unknown & Dry savannah \\
\hline & & An. rivulorum-like & Exophilic & Zoophilic & Unknown & Dry savannah \\
\hline \multirow[t]{4}{*}{ An. nili group } & \multirow[t]{4}{*}{4} & An. nili & Exophilic & Anthropozoophilic & High & Countrywide \\
\hline & & An. ovengensis & Exophilic & Anthropozoophilic & Moderate & Forest \\
\hline & & An. carnevalei & Exophilic & More zoophilic & Minor & Forest \\
\hline & & An. somalicus & Exophilic & Zoophilic & None & Forest \\
\hline An. moucheti group & 3 & An. moucheti & Endophilic/ exophilic & Anthropophilic & High & Forest \\
\hline \multirow[t]{5}{*}{ An. coustani group } & \multirow[t]{5}{*}{8} & An. coustani & Exophilic & More zoophilic & Moderate & Countrywide \\
\hline & & An. ziemanni & Exophilic & More zoophilic & Moderate & Countrywide \\
\hline & & An. paludis & Exophilic & Anthropophilic & Moderate & Forest \\
\hline & & An. namibiensis & Exophilic & Anthropophilic & Unknown & Forest \\
\hline & & An. obscurus & Exophilic & Zoophilic & Unknown & Forest \\
\hline \multirow{6}{*}{$\begin{array}{l}\text { An. marshalli-han- } \\
\text { cocki group }\end{array}$} & \multirow[t]{6}{*}{12} & An. marshallii & Exophilic & More zoophilic & Minor & Forest \\
\hline & & An. hancocki & Exophilic & Anthropophilic & Minor & Forest \\
\hline & & An.brohieri & Exophilic & Zoophilic & Unknown & Savannah \\
\hline & & An. wellcomei & Exophilic & More zoophilic & Minor & Forest \\
\hline & & An. njombiensis & Exophilic & Zoophilic & None & Forest \\
\hline & & An. hargreavsi & Exophilic & Zoophilic & None & Forest \\
\hline An.pharoensis & 1 & An.pharoensis & Exophilic & Anthropozoophilic & Moderate & Sahelian and savannah \\
\hline An. rufipes group & 2 & An.rufipes & Exophilic & Anthropozoophilic & Moderate & Sahelian and savannah \\
\hline
\end{tabular}




\section{Anopheles gambiae complex}

Members of the Anopheles gambiae species complex found in Cameroon include An. gambiae (s.s.), An. arabiensis, An. coluzzii and An. melas [158, 161]. While Anopheles arabiensis is restricted to the northern arid and semi-arid zone, An. gambiae (s.s.) and An. coluzzii are widely distributed across the country $[11,158]$. Anopheles gambiae (s.s.) and An. coluzzii are highly anthropophylic and closely related to anthropogenic environments for resting and oviposition [162, 163]. Yet recent findings in different ecological settings suggested high phenotypic plasticity of feeding, biting or resting behaviours for $A n$. gambiae (s.s.) and An. coluzzi with increased usage of protection measures such as LLINs [12, 164-166]. It is likely that this might reflect a shift in the feeding or resting behaviour of these species or could just be the suppression of most vulnerable taxa by the use of indoor based interventions. More malaria parasite transmission cases occurring outdoors have been reported in different epidemiological settings [101], thus suggesting the need for interventions targeting outdoor biting mosquitoes such as spatial repellents or larval control [167]. Similar strategy would apply to $A n$. arabiensis which is exophagic and exophilic and feeds on both humans and cattle [53]. This species behavior has not been deeply affected by the implementation of control measures across the country, probably because of the high number of people frequently sleeping outdoor part of the year due to heat and hot temperature in the northern part of the country where this species predominates [53]. Rapid expansion of insecticide resistance as a result of increased use of LLINs and pesticides in agriculture has been reported in this species [168, 169]. Anopheles coluzzii, An. gambiae (s.s.) and An. arabienis are frequently involved in malaria parasite transmission in Cameroon and sometimes in sympatry, with infection rates varying from 2 to $10 \%$, and entomological inoculation rate (EIR) reaching up to 400 infective bites per person per year depending on the epidemiological setting $[11,52,53]$. By contrast, there is still no record on $A n$. melas implication in malaria parasite transmission in Cameroon, but this species is considered as a good vector in the neighbouring Equatorial Guinea [170]. Further comparative studies are required between An. melas populations from Cameroon and Equatorial Guinea to understand their differences in vectorial capacity.

Although An. gambiae (s.s.) and An. coluzzii overlap to a large extent, species distribution modelling studies revealed differences in the ecological niche of the two species [161]. Anopheles coluzzii and An. gambiae (s.s.), segregate along two gradients: distance from the coastline and altitude, with $A n$. coluzzii displaying a bimodal distribution, predominating in dryer savannah and along the western coastal fringe [171]. Recent evolutionary studies testing the relationship between reproductive isolation, ecological divergence and hybrid viability suggested a positive association between the strength of reproductive isolation and the degree of ecological divergence. These findings indicate that post-mating isolation does contribute to reproductive isolation between these species [172]. At micro-environmental level, studies conducted in the city of Yaoundé indicated that An. gambiae (s.s.) and $A n$. coluzzii could segregate along the urbanization gradient with $A n$. coluzzii being more adapted to urban settings and $A n$. gambiae (s.s.) in rural settings [173]. The current speciation between $A n$. coluzzii and An. gambiae (s.s.) and their adaptation to different type of habitats in the urban environment including polluted sites, artificial containers and possible changes in their vectorial competency [99, 100, 174] warrants further investigations. In Cameroon according to the latest population census, over $52 \%$ of the population live in urban settings and this population is projected to grow faster in the next decades [40]. Studies conducted so far in the main cities of Cameroon (Yaoundé and Douala) suggested that unplanned urbanization and the practice of urban agriculture maintain high malaria transmission risk by providing suitable habitats for mosquitoes [93, 99, 101, 175]. If no measures are taken, this could lead to more malaria cases in urban settings and high incidence of severe malaria in both adults and children since people living in urban settings have less premunition against malaria [176-178].

\section{Anopheles funestus group}

Anopheles funestus is a group of 11 species distributed across Africa. In Cameroon four species have been reported including $A n$. funestus, An. leesoni, An. rivulorum and $A n$. rivulorum-like which differ from the typeform by slight genetic differences [179]. Although this variant has been reported from Cameroon, Burkina Faso and South Africa, its taxonomic status and role as vector are still unclear and warrant further investigations in order to know if it could be a target for vector control interventions $[179,180]$. Yet a modified version of the species complex PCR originally set up by Koekemoer et al. [181] was designed by Cohuet et al. [179] to enable identification of this variant. Within the members of the group present in Cameroon only An. funestus and $A n$. leesoni have so far been reported infected [11, 160]. Anopheles funestus is highly endophilic and feed predominantly on humans $[182,183]$. This species was responsible for infection rate of up to $10 \%$ and EIR of up to 350 infected bites per person per year [11, 91, 184]. Genetic analysis conducted on $A n$. funestus using microsatellite markers reported high panmixia between vector populations and a genetic differentiation of populations 
consistent with isolation by distance [185]. Cytogenetic studies and fine-scale mapping studies, demonstrated high level of chromosomal heterogeneity both within and between populations, which could reflect the influence of both ecotypic variations and environmental factors [185188]. Although there have been several studies exploring the bionomics, susceptibility to insecticides, resistance mechanisms over recent years [57, 59, 95, 189-197], the influence of the intensification of control measures on the species bionomics, genetic structure and vectorial capacity is not well understood and the following could impede the successful completion of disease elimination programmes to be conducted in Cameroon.

\section{Anopheles nili group}

This group consists of four species including $A n$. nili (s.s.) (the type-form), An. carnevalei, An. ovengensis and An. somalicus $[10,198,199]$. Anopheles nili is by far the most important vector species of the group. Anopheles ovengensis and An. carnevalei have been found infected in Cameroon [11, 90], while An. somalicus is strictly zoophilic and is not therefore involved in malaria parasite transmission [90, 199]. Anopheles nili and An. ovengensis bite indoors as well as outdoors but rest mainly outdoors. Anopheles carnevalei bites exclusively outdoors [90, 199]. There has been substantial progress in the recent years regarding genetic studies on An. nili. These studies include the development and chromosomal mapping of microsatellites makers, development of chromosome maps for An. nili, An. ovengensis and An. carnevalei, and development of single nucleotide polymorphisms (SNPs) for fine scale genomic analysis [200-203]. Genetic structure analysis conducted for members of the An. nili group using microsatellites, sequencing of ribosomal DNA and fine-scale mapping indicated high level of genetic differentiation between these species [203, 204]. Studies conducted on the type-form An. nili (s.s.) suggested high gene flow between populations situated across the distributional range of the species in West and Central Africa [205]. However, a cryptic genetic diversity within An. nili (s.s.) was reported in the deep equatorial forest environment of South Cameroon, reflecting a complex demographic history for this major malaria vector in this environment [204]. Cytogenetic analysis indicated the occurrence of two chromosomal inversions displaying high frequencies in the savannah compared to the forest populations that are purported to be related to local selection or adaptation to climatic cline [201]. Anopheles nili is highly predominant in villages near permanent rivers which constitute it breeding sites and can easily be localized and targeted for vector control, but due to their high outdoor feeding and resting behaviour, members of the An. nili group are less affected by indoor based interventions. Also, their implications as bridge vector for primate-infecting Plasmodium spp. as well as for other wild parasites or virus need to be evaluated. Such information could be crucial in the perspective of malaria elimination in central and West Africa where mosquitoes of the An. nili group play important roles in malaria parasite transmission.

\section{Anopheles moucheti group}

This group consists of three sub-species namely $A n$. moucheti moucheti (hereafter An. moucheti) (the typeform), An. moucheti nigeriensis and An. moucheti bervoetsi. These subspecies could be distinguished from one another by slight morphological characters or by the use of a PCR molecular assay [206-208]. In Cameroon, only the type-form of An. moucheti is present, and is mainly found in the equatorial forest domain where it has been reported to be responsible for transmission rates reaching 300 infective bites/person/year, particularly in villages situated along slow moving rivers [11, 88, 199, 209]. Genetic studies conducted on this mosquito population indicated high genetic variability and low genetic differentiation between populations distributed across the range of the species in Cameroon, the Democratic Republic of Congo and Uganda [210, 211]. Recent studies allowed the development of a chromosomal map for the species [212]. In the light of studies conducted so far in Gabon [118], it is not clear whether An. moucheti populations in Cameroon are competent for the transmission of Plasmodium spp. infecting the great apes. Because of the circulation of primate-infecting Plasmodium in the equatorial forest region, it could be interesting to run experimental infection assay with An. moucheti to determine its competence for these primate-infecting Plasmodium species and for other haemoparasites found in the wild. This information could be determinant for identifying sources for zoonosis infections or those in circulation in the forest regions. More recently, studies conducted in the equatorial forest region indicated a change in the biting and resting behaviour from indoor to outdoor of this species following the intensification of vector control measures in Cameroon [164]. The implication of these findings on the performance of control measures need to be assessed in various sites and new strategies to mitigate the impact of outdoor and residual transmission developed.

\section{Vector control in Cameroon}

In the 1940s during the colonial period, mosquito control was conducted by hygiene and sanitation services in the two main cities of Cameroon, Douala and Yaoundé [213]. Control interventions during that period were mainly based on the strict policy of regular inspection and 
destruction of all temporary larval habitats near houses, elimination of garbage near houses and clearing of bushes. Inhabitants from the two cities were instructed to keep their nearby environment clean and if this was not done, they could be sent to jail [213, 214]. For permanent water collections, the following compounds were used as insecticides: formol, pyrethre powder, tobacco smoke, phenic acid, quinoleine and cresyl [213, 215]. From 1949, larval control operations and house spraying were undertaken regularly by hygiene services in both Douala and Yaoundé to stop malaria parasite transmission [216]. These measures were later replaced by the launching of malaria eradication campaigns which began in 1953 using indoor residual spraying (IRS) with DDT, dieldrin and $\mathrm{HCH}$ as the main insecticides [216-218]. These IRS campaigns which were initiated by the World Health Organization (WHO) were replicated in different countries across sub-Saharan Africa in Senegal, Burkina Faso, Liberia, Benin and Tanzania [218]. Pilot IRS campaigns in Cameroon were conducted in Yaoundé and the northern city of Maroua and surrounding communities covering a total population of 750,000 and 250,000 inhabitants respectively. Campaigns in Yaoundé and its surrounding areas were conducted from 1953 to 1960 and was divided in two large areas; the western zone sprayed using DDT while the eastern zone was treated using dieldrin $[216,218]$. These campaigns resulted in a significant decrease in malaria parasite transmission, vector density and the incidence of malaria cases to close to zero [216], but the programme was interrupted in the 1960s due mainly to financial constraints. In the northern part of the country, Maroua and its surroundings, IRS campaigns were undertaken from 1953 to 1961 using DDT only. In 1959, DDT resistance was reported in An. gambiae populations $[217,219]$. By contrast to the control programme initiated in Yaoundé, no reduction in vector density, malaria parasite transmission nor of the incidence of cases was reported [217]. Other factors which contributed to the poor performance of the programme were the poor residual effect of the insecticide on different housing material, the inaccessibility of some villages during the rainy season or the exophilic and opportunistic behaviour of the main vector in the area, An. arabiensis, whereas in Yaoundé vector populations were found to be highly endophilic [217]. The programme was later stopped in 1961 due to it poor performance. Similarly to Cameroon, the global malaria eradication campaigns piloted by the WHO across Africa also failed. As a consequence, the WHO initiated the Garki Malaria Project in Kano, Nigeria [220]. This pilot project intended to better appraise the epidemiology of malaria and assess whether malaria elimination could be achievable in West African savanna area with high and perennial malaria parasite transmission using mass drug administration and IRS [220]. Although the project was well thought, it also failed despite lessons learn from previous campaigns and the use of a different strategy associating mathematical modelling analysis, intensive application of propoxur in houses and widespread distribution of the drugs chloroquine and sulfadoxine-pyrimethamine to the population [220]. The prevalence of malaria only dropped from $80 \%$ to $30 \%$ after a three-year campaign and returned to $80 \%$ one year after the stoppage of the programme [220]. The authors of the study indicated that high entomological inoculation rate due to principal vectors and the complexity of malaria ecology in the area, were the reasons of the programme failure. Yet the Garki Project provided a high number of findings which are relevant nowadays and for future control operations [221]. The failure of the global malaria eradication campaign and the very limited impact of the Garki Project interventions throw light on the heterogeneous epidemiology of malaria across Africa and the need for a better understanding of the factors affecting disease transmission.

Following the unsustained results of malaria pre-eradication and eradication campaigns across sub-Saharan Africa [222, 223], the WHO adopted a change of strategy from vector control to prioritizing treatment and chemoprophylaxis [224]. Cameroon also aligned its policy on this same direction. The massive use of chloroquine during the 1960s through to the 1990s was associated with the appearance of resistance, which spread widely across the continent [225]. In Cameroon, the first cases of chloroquine resistance were recorded in the early 1980s [124, 226-228].

A large-scale vector control programme was resumed in the country in the 1990s with the deployment of pyrethroid-treated nets. Several pilot programmes were conducted across Cameroon. Trials conducted in Edéa, Mbébé, Ebogo, Kumba and Mbandjock in forest and humid savannah areas against vector species such as $A n$. gambiae (s.l.), An. funestus, An. nili and An. moucheti, provided sufficient evidence for the scale-up of this intervention across the country [83, 89, 229-231]. At the level of the Ministry of Health, key actions were undertaken to speed up the scale-up of treated nets across the country to prevent malaria. This included: (i) the development of a malaria control strategic plan with the goal of achieving $60 \%$ coverage of the target population by 2006 ; (ii) the creation and equipment of 10 reference units for bed-net impregnation in the ten regions of the country; (iii) the training of local staff to undertake bed-net impregnation; (iv) the organisation of free distribution campaigns of bed-nets to pregnant women and children of under five years-old; and (v) the inclusion of up to 1733 NGO and local community groups in the promotion of the use of 
treated nets. These actions permitted to attain a coverage rate which gradually increased from $5.7 \%$ in 2003, $16.6 \%$ in 2004 and $39.5 \%$ in 2005 , with yet a high variability of the level of coverage between regions noted [232].

Nowadays, malaria prevention in Cameroon mainly relies on the use of long-lasting insecticidal nets (LLINs) (of different brands, e.g. PermaNet, Olyset, Interceptor) [21, 233, 234]. Since 2004 three important free distributions of treated nets have been conducted across the country. The first in 2004-2005 permitted the distribution of up to 2 million insecticide treated nets to pregnant women and children younger than 5 years of age. The second campaign conducted in 2011 allowed the switch from ITN to LLIN with the distribution of up to 8 million LLINs to the general population, while the third in 2015 permitted the distribution of over 12 million LLINs to the entire population $[1,235]$. It is estimated that $77 \%$ of the population own at least a treated net and that $58 \%$ of the population use these nets regularly [1]. Yet heterogeneous patterns between LLINs ownership and utilization have been reported in different epidemiological settings across the country [133, 137, 236-239]; this is considered as an important factor affecting the performance of treated bed-nets in Cameroon. Although several sensitization campaigns through the media, or using community workers or through meetings with the communities have been conducted across the country to increase bednet usage [236] it remains low. Disparities in bed-net ownership and usage between regions in Cameroon could be linked to cultural, social practices or lifestyle [240]. It is becoming urgent to involve more social science specialists in vector control interventions in order to address population adherence to these interventions. Since the introduction of LLINs, significant reduction of both entomological and epidemiological indicators has been documented across the country by different studies [24, 199] thus stressing the importance of this tool for malaria control in the country. From national statistics it appears that some regions display high coverage or usage rate of LLINs compared to others; however, these same regions, equally display high estimates of malaria prevalence and transmission [1]. This contradicting figure derives from the fact that the true usage or coverage rate could be underestimated since self-reports through questionnaires are usually used to collect information from households [24]. In a recent study in the city of Yaoundé, it was reported that self-reporting overestimated by $10-30 \%$ the average usage rate of bed-net by the population compared to the national level [136]. Self-reported measures have been found to overestimate ITN adherence by over $13 \%$ elsewhere [241]. It is becoming important that, different methods be used to collect information from households to assess coverage and utilization of LLINs. In Zambia, mass distribution of LLNs through door-to-door delivery to households in rural settings associated with net hanging and face-toface health education on LLIN use and ways of reducing net wear and tear were found to increase the usage and coverage rates [242]. If correctly used and high coverage rate achieved, LLINs could have a central role in the path to achieving malaria elimination in the country. It should be interesting to preserve LLINs efficacy by assessing the actual sustainability of the use of LLINs, practices leading to less utilization of nets after a certain time, the quality of nets delivered to the population, the persistence of active ingredient on nets and the efficacy of LLINs at different periods.

In addition to LLINs, pilot vector control trials (larviciding and indoor residual spraying) have been launched in the country $[14,16]$. The larviciding trial is undertaken in the city of Yaounde by the team of OCEAC in collaboration with the NMCP. This programme intends to assess the efficacy of larviciding using a combination of Bacillus thuringiensis israelensis and B. sphaericus for controlling malaria parasite transmission and mitigating the impact of insecticide resistance. This study intends to provide critical information which could be useful for adopting larviciding as a complementary approach for controlling malaria parasite transmission in major cities in Cameroon [167]. The second programme conducted by the VectorLink project under the sponsorship of the US President Malaria Initiative (PMI), is indoor residual spraying. This programme intends to assess the impact of indoor residual spraying for eliminating malaria in eligible sentinel sites in the two northern regions of the country [14]. The programme, which is at its initial phase, intends to provide critical information for the scale-up of similar interventions in eligible sites across the country. The city of Yaoundé is also benefiting from the PADY programme which mainly focus on hygiene and sanitation through the construction of drains on the bed of main rivers crossing the city in order to reduce permanent breeding opportunities for mosquitoes [15, 16]. However, the deployment of these tools should be accompanied by stringent routine entomological and epidemiological surveillance activities to monitor shift in incidence of cases, mosquito biting rate, entomological inoculation rate and insecticide resistance and operational issues well described and how they are solved to avoid the same problems to other teams.

\section{Insecticide resistance}

The increased use of treated bednets and the use of insecticides in agriculture are all considered to select for insecticide resistance in mosquito populations [167]. Insecticide resistance is recognized as a serious threat for 
control interventions implemented in the country. The first cases of insecticide resistance in Cameroon were reported in the 1950s during malaria eradication pilot campaigns with An. gambiae (s.l.) populations exhibiting resistance to both dieldrin and DDT [218]. A recent review of data from the 1990s to 2017 indicated rapid expansion of insecticide resistance particularly to pyrethroids and DDT in the main malaria vectors An. gambiae, An. coluzzii, An. arabiensis and An. funestus across the country [167]. During the last decade important variations in the level of susceptibility of An. gambiae vector populations to insecticides have been documented [169, 243-246] affecting the efficacy of LLINs [247, 248]. However, a randomized control trial study conducted between 2013 and 2015 in 38 clusters in the northern part of the country where An. arabiensis, An. gambiae, An. coluzzii and $A n$. funestus are present, suggested no influence of insecticide resistance on LLINs efficacy in preventing against malaria parasite transmission [51]. Pyrethroid resistance was found to be conferred by $k d r$ West and East alleles and metabolic-based mechanisms [99, 249, 250]. Main genes reported to be involved in DDT and pyrethroid resistance in both An. gambiae and An. coluzzii include cyp $6 p 3$, cyp6m2, cyp6p4, cyp $9 k 1$, gstd1-6 cyp $6 z 3$ and gstd 1-4. There is still a paucity of data on the distribution of main candidate detoxification genes and of the intensity of resistance in different ecological settings. The primary mechanism conferring resistance to DDT and pyrethroids in An. arabiensis is mainly a metabolic detoxification mechanism. However, over recent years, an increase in the prevalence of target-site resistance, $k d r 1014 \mathrm{~F}$ and $1014 \mathrm{~S}$ alleles was also reported for this species [92, 167, 251]. Despite widespread distribution of $k d r$ resistance alleles in An. gambiae (s.l.) populations, $k d r$ tend to be less likely than metabolic resistance to induce control failure [252].

Although less common, resistance to bendiocarb has also been reported [99, 250]. This resistance was not associated to the presence of the ACE 1 target-site mutation but is likely mediated through metabolic mechanisms [250]. Yet the presence of the ACE 1 mutation is suspected in the country [253]. This probably discards carbamates as an alternative to pyrethroids for vector control in Cameroon whereas organophosphates, which are still largely efficient, could be indicated for future vector control interventions.

With regard to An. funestus, several studies reported increased prevalence of insecticide resistance in this vector in both forest and savannah areas [59, 95, 194]. This resistance is mainly mediated by metabolic-based mechanisms since no $k d r$ have been found in this species. The following mechanisms were reported to induce resistance: $119 \mathrm{~F}-\mathrm{GSTe} 2$ was found to confer resistance to DDT and pyrethroids; 296S-RDL mutation was associated to resistance to dieldrin; and several P450 monooxygenase genes were reported to be involved in resistance to both DDT and pyrethroids [189, 194]. The resistance gene 119F-GSTe2 was reported to influence life traits of both adults and larval stages of An. funestus [254].

With the continuous expansion of insecticide resistance in vector populations, the global programme for insecticide resistance management recommends [252] the implementation of measures to maintain the efficacy and the lifespan of current and future malaria control tools as a long-term goal. Short-term objectives are to preserve the susceptibility of major malaria vectors to pyrethroids and other classes of insecticides until new insecticides become available by using integrated control approaches which combine different interventions or tools or rotation of interventions at different periods.

\section{Conclusions}

The present review provides an update of the situation of malaria, vectors bionomics, Plasmodium species distribution, case management, drug resistance, disease prevalence and control measures in Cameroon. Although significant progress has been made over the last decade to curb the disease burden, malaria is still largely prevalent across the country and displays a high complexity and heterogeneity. As the review highlighted, several challenges affect both the treatment, case management, operational implementation and vector control interventions and warrant further consideration. Malaria treatment is affected by the decrease in drug efficacy and rapid spread of resistance in $P$. falciparum populations to sulfadoxine-pyrimethamine and 4-aminoquinoline. Although artemisinin is not yet affected, there is a need to remain vigilant with the emergence of artemisinin resistance in Southeast Asia which can spread to Africa through migrants or independently emerge. In this regard, recent molecular tools could be determinant for tracking resistant genes and control failures. On the vector side, the rapid emergence of insecticide resistance that is affecting almost all compounds used in public health is a major threat for current malaria vector control programmes. In addition to core interventions (LLINs, and IRS), which mainly rely on insecticides, additional control tools such as spatial repellents, larval source management, new generation LLINs, durable wall lining, cattle treated with insecticides need to be added to address these challenges. Malaria vaccine development is witnessing different challenges. RTS S/AS01 the most advanced candidate vaccine has shown low efficacy and faces some safety concerns especially for young children hence, limiting performance of this tool for eliminating malaria in intense transmission settings $[255,256]$. So 
far malaria prevention through the use of vector control measures is considered to be highly cost-effective than other control interventions (e.g. mass drug administration) and scale-up has to be prioritized in all scenarios [257]. Indeed, the large scale-up of LLINs and IRS is considered to have averted an estimated 663 million clinical cases of malaria worldwide between 2001 and 2015 [258]. This highlights the central role that vector control has to play in the elimination of malaria. Thus, in order to achieve malaria elimination, the core interventions alone may not be sufficient. Adopting an integrated control approach is becoming critical for sustainable control of malaria in Cameroon. The combination of interventions suited for each epidemiological setting such as LLINs with larval source management or wall lining could be indicated for hyperendemic stratum experiencing high insecticide resistance. On the other side, combinations associating LLINs to spatial repellents could be indicated for hyperendemic stratum with outdoor malaria parasite transmission. In hypoendemic settings with limited breeding habitats or less diversity in vector species, the use of LLINs together with larval source management (LSM), attractive toxic sugar baits (ATSB) or gene drive could be indicated. In stratum displaying seasonal malaria parasite transmission, the use of LLINs with IRS spraying could be indicated for also managing insecticide resistance. New tools such as new generation nets or new generation IRS now available could be deployed to replace former LLIN formulations or to sustain control efforts. Although this has not been included in the present review, strengthening the health care system is part of the global effort for insuring sustainable malaria elimination. Because most of the current interventions are affected by operational challenges capacity building at different levels (local, community or national level) becomes central to ensure appropriate implementation of operational actions on the field. It is also relevant to stress the need for collaboration or networking to address capacity building issues. In this regard it could be indicated to revisit the achievement of the African Network on Vector Resistance to insecticides (ANVR) who acted between 2000 and 2004. During its short live period, the ANVR network was able to update and develop technical documents, standardize protocols for testing malaria vector susceptibility, provide guidelines for insecticide resistance management and contribute to capacity building. The revamping of such network and extending its actions to vector bionomics and vector control could be determinant to foster global elimination efforts across the sub-regions and sub-Saharan Africa. In the perspective of malaria elimination in Cameroon, it is important that challenges actually affecting control interventions be better identified and understood, and only intervention strategies tailored to be amenable to defined local epidemiological settings be taken into consideration. However, in each case, the deployment of any intervention should be accompanied by stringent routine entomological and epidemiological surveillance activities to monitor the success of the intervention and inform policy in real time.

\begin{abstract}
Abbreviations
LLINs: long-lasting insecticidal nets; IRS: indoor residual spraying; WHO: World Health Organization; NMCP: national malaria control programme; HCH: hexachlorocyclohexane; ITN: insecticide treated nets; LSM: larval source management; ANVR: African Network on Vector Resistance to insecticides; OCEAC: Organization for the Coordination of the fight against Endemic diseases in Central Africa.
\end{abstract}

\section{Authors' contributions}

CW and CAN conceived and designed the study protocol. NC, NF, BJ, AAP, EJ, SEA and WC critically revised the manuscript. CAN with contribution of other authors (NC, NF, BJ, EJ and WC) interpreted, analysed data and wrote the paper. All authors read and approved the final manuscript.

\section{Funding}

This work received financial support from Wellcome Trust senior Fellowship in Public Health and Tropical Medicine (202687/Z/16/Z) awarded to CAN. The funding body did not have any role in the design, collection of data, analysis and interpretation of data and in writing of the manuscript.

\section{Availability of data and materials \\ The datasets supporting the findings of this article are included within the article.}

Ethics approval and consent to participate

Not applicable.

\section{Consent for publication}

Not applicable.

\section{Competing interests}

The authors declare that they have no competing interests.

\section{Author details}

${ }^{1}$ Laboratoire de Recherche sur le Paludisme, Organisation de Coordination pour la lutte contre les Endémies en Afrique Centrale (OCEAC), B. P.288 Yaoundé, Cameroun. ${ }^{2}$ Department of Biological Sciences, Faculty of Medicine and Pharmaceutical Sciences, University of Douala, P.O. Box 24157, Douala, Cameroon. ${ }^{3}$ Centre for Research in Infectious Disease (CRID), P.O. Box 13591, Yaoundé, Cameroon. ${ }^{4}$ Faculty of Sciences, University of Yaoundé I, P.O. Box 337, Yaoundé, Cameroon. ${ }^{5}$ Vector Biology Liverpool School of Tropical medicine Pembroke Place, Liverpool, UK. ${ }^{6}$ Laboratory for Vector Biology and control, National Reference Unit for Vector Control, The Biotechnology Center, Nkolbisson-University of Yaounde I, P.O. Box 3851, Messa, Yaounde, Cameroon. ${ }^{7}$ Department of Biochemistry, Faculty of Science, University of Yaounde I, Yaounde, Cameroon. ${ }^{8}$ Institute for Insect Biotechnology, Justus Liebig University Gießen, Winchester Str. 2, 35394 Gießen, Germany.

Received: 5 May 2019 Accepted: 18 October 2019

Published online: 26 October 2019

\footnotetext{
References

1. Minsante. Xlième Journée mondiale de lutte contre le paludisme "prêt à vaincre le paludisme" Nous sommes la génération qui peut éliminer le paludisme. Dossier de Presse. Minsante. 2018:1-20.

2. Massoda Tonye SG, Kouambeng C, Wounang R, Vounatsou P. Challenges of DHS and MIS to capture the entire pattern of malaria parasite
} 
risk and intervention effects in countries with different ecological zones: the case of Cameroon. Malar J. 2018;17:156.

3. NMCP. National Malaria Control Programme annual report MINsante Cameroon. 2015.

4. WHO. World malaria report 2015. Geneva: World Health Organization; 2015.

5. Tabue RN, Njeambosay BA, Zeukeng F, Esemu LF, Fodjo BA, Nyonglema $\mathrm{P}$, et al. Case definitions of clinical malaria in children from three health districts in the North Region of Cameroon. BioMed Res Int. 2019;2019:9709013

6. Fru-Cho J, Bumah V, Safeukui I, Nkuo-Akenji T, Titanji V, Haldar K. Molecular typing reveals substantial Plasmodium vivax infection in asymptomatic adults in a rural area of Cameroon. Malar J. 2014;13:170

7. Ngassa Mbenda HG, Das A. Molecular evidence of Plasmodium vivax mono and mixed malaria parasite infections in Duffy-negative native Cameroonians. PLoS ONE. 2014;9:e103262.

8. Russo G, Faggioni G, Paganotti GM, Djeunang Dongho GB, Pomponi A, De Santis R, et al. Molecular evidence of Plasmodium vivax infection in Duffy negative symptomatic individuals from Dschang, West Cameroon. Malar J. 2017:16:74.

9. PNLP. Plan Strategique nationale de lutte contre le paludisme 2011-2015. Rapport Minsante Cameroun; 2012. p. 1-82.

10. Hervy JF, Goff G, Geoffroy B, Herve JP, Manga L, Brunhes J. Les Anophèles de la région afrotropicale. CD-ROM. Paris: ORSTOM; 1998.

11. Antonio-Nkondjio C, Kerah C, Simard F, Awono-Ambene H, Mouhamadou C, Tchuinkam T. Complexity of malaria vectorial system in Cameroon: contribution of secondary vectors to malaria transmission. J Med Entomol. 2006;43:1215-21.

12. Fontenille D, Simard F. Unravelling complexities in human malaria transmission dynamics in Africa through a comprehensive knowledge of vector populations. Comp Immun Microbiol Infect Dis. 2004:27:357-75.

13. Minsanté. Journée mondiale de lutte contre le paludisme 2019 au Cameroun. https://cm.ambafrance.org/Journee-mondiale-de-lutte-contr e-le-paludisme-2019-au-Cameroun. Accessed 24 May 2019.

14. Malaria Operational Plan Cameroon_-President's Malaria Initiative. Yaoundé: USAID; 2017.

15. Kanga $M$, Jallow $M, B a M$, Kane $M, M b a y e ~ E$. Deuxième phase du projet d'assainissement de la ville de Yaoundé (PADY.2): Groupe de la Banque Africaine de Développement. Rapport d'Evaluation Departement OWAS; 2013. p. 1-17.

16. Antonio-Nkondjio C, Ndjondo-Sandjo N, Awono-Ambene H, Wondji C. Implementing a larviciding efficacy or effectiveness control intervention against malaria vectors: key parameters for success. Parasit Vectors. 2018;11:57.

17. Apinjoh TO, Mugri RN, Miotto O, Chi HF, Tata RB, Anchang-Kimbi JK, et al. Molecular markers for artemisinin and partner drug resistance in natural Plasmodium falciparum populations following increased insecticide treated net coverage along the slope of mount Cameroon: cross-sectional study. Infect Dis Poverty. 2017;6:136.

18. Anchang-Kimbi JK, Nkweti VN, Ntonifor HN, Apinjoh TO, Tata RB, Chi HF. Plasmodium falciparum parasitaemia and malaria among pregnant women at first clinic visit in the mount Cameroon area. BMC Infect Dis. 2015:15:439.

19. Menard S, Tchoufack JN, Maffo CN, Nsango SE, Iriart X, Abate L, et al. Insight into k13-propeller gene polymorphism and ex vivo DHAresponse profiles from Cameroonian isolates. Malar J. 2016;15:572.

20. Moyeh MN, Njimoh DL, Evehe MS, Ali IM, Nji AM, Nkafu DN, et al. Effects of drug policy changes on evolution of molecular markers of Plasmodium falciparum resistance to chloroquine, amodiaquine, and sulphadoxine-pyrimethamine in the South West Region of Cameroon. Malar Res Treat. 2018;2018:7

21. Programme national de lutte contre le paludisme. Plan stratégique national de lutte contre le paludisme-Cameroun: 2014-2018. Yaoundé: Rapport Ministère de la Santé Publique; 2014

22. Programme National Malaria Control. Directorates for management and use of artemisinine-based combination therapies (ACT) in Cameroon. Yaounde: Ministry of Public Health Report; 2007. p. 22.

23. Sayang C, Gausseres M, Vernazza-Licht N, Malvy D, Bley D, Millet P. Treatment of malaria from monotherapy to artemisinin-based combination therapy by health professionals in urban health facilities in Yaounde, central province, Cameroon. Malar J. 2009:8:176.
24. Statistique INdl. Chapitre 4 Caractéristiques population.pdf. Annuaire Statistique du Cameroun 2011. p. 72-81.

25. BUCREP. Troisième recencement générale de la population et de l'habitat. Third general population and housing census Cameroun. Yaoundé: Rapport de présentation des résulstats définitifs République du Cameroun; 2010. p. 1-65.

26. Sighomnou D. Analyse et definition des regimes climatiques et hydrologiques du Cameroun: perspectives d'evolution des ressources en eau. PhD Thesis, University of Yaoundé 1, Yaoundé; 2004.

27. Serdeczny O, Adams S, Baarsch F, Coumou J, Robinson A, Hare B, et al. Climate change impacts in sub-Saharan Africa: from physical changes to their social repercussions. Reg Environ Change. 2016;15:3-18.

28. Peyrefitte C, Rousset D, Pastorino B, Pouillot R, Bessaud M, Tock F, et al. Chikungunya virus, Cameroon, 2006. Emerg Infect Dis. 2007;13:768-71.

29. Demanou M, Pouillot R, Grandadam M, Boisier P, Kamgang B, Herve JP. Evidence of dengue virus transmission and factors associated with the presence of anti-dengue virus antibodies in humans in three major towns in Cameroon. PLoS Negl Trop Dis. 2014;8:e2950.

30. Demanou M, Antonio-Nkondjio C, Ngapana E, Rousset D, Paupy C, Manuguerra JC, et al. Chikungunya outbreak in a rural area of western Cameroon in 2006: a retrospective serological and entomological survey. BMC Res Notes. 2010;3:128.

31. Leroy E, Nkoghe D, Ollomo B, Nze-Nkogue C, Becquart P, Grard G, et al. Concurrent chikungunya and dengue virus infections during simultaneous outbreaks, Gabon, 2007. Emerg Infect Dis. 2009;15:591-3.

32. Moyen N, Thiberville SD, Pastorino B, Nougairede A, Thirion L, Mombouli JV, et al. First reported chikungunya fever outbreak in the Republic of Congo, 2011. PloS ONE. 2014;9:e115938.

33. Fontenille D, Toto JC. Aedes (Stegomyia) albopictus (Skuse), a potential new dengue vector in southern Cameroon. Emerg Infect Dis. 2001:7:1066-7.

34. Simard F, Nchoutpouen E, Toto JC, Fontenille D. Geographic distribution and breeding site preference of Aedes albopictus and Aedes aegypti (Diptera: Culicidae) in Cameroon, Central Africa. J Med Entomol. 2005:42:726-31.

35. Weetman D, Kamgang B, Badolo A, Moyes CL, Shearer FM, Coulibaly M, et al. Aedes mosquitoes and Aedes-borne arboviruses in Africa: current and future threats. Int J Environ Res Public Health. 2018;15:220.

36. Sinka M, Bangs M, Manguin S, Rubio-Palis Y, Chareonviriyaphap T, Coetzee $\mathrm{M}$, et al. A global map of dominant malaria vectors. Parasit Vectors. 2012;5:69.

37. Winskill P, Walker PG, Cibulskis RE, Ghani AC. Prioritizing the scale-up of interventions for malaria control and elimination. Malar J. 2019;18:122.

38. Moonen B, Cohen J, Snow R, Slutsker L, Drakeley C, Smith D, et al. Operational strategies to achieve and maintain malaria elimination. Lancet. 2010:376:1592-603.

39. Ogden N, Gachon P. Climate change and infectious diseases: what can we expect? Can Commun Dis Rep. 2019;45:76-80.

40. BUCREP. Rapport national sur l'etat de la population Edition 2014: Regard sur le genre au Cameroun. Yaoundé: BUCREP; 2014. p. 1-99.

41. Partenariat pour les Forêts du Bassin du Congo. https://pfbc-cbfp.org/ search.html?keywords=far+north+cameroon. Accessed 15 July 2019.

42. Serafini S, Regard S, Mahounde Bakari I, Massenet D. Presumptive clinical diagnosis of malaria in children in a hospital in the north region (Cameroon). Bull Soc Path Exot. 2011:104:271-373.

43. Couprié B, Claudot Y, Same- Ekobo A, Issoufa H, Léger-Debruyne M, Tribouley J, et al. Epidemiologic study of malaria in the rice-growing regions of Yagoua and Maga (North Cameroon). Bull Soc Path Exot. 1985;78:191-204.

44. Same Ekobo A, Fondjo E, Eouzan JP. Grands travaux et maladies à vecteurs au Cameroun Impact des aménagements ruraux et urbains sur le paludisme et autres maladies à vecteurs., Paris: IRD Ed, Collection expertise collégiale; 2001.

45. Kwenti TE, Kwenti TDB, Latz A, Njunda LA, Nkuo-Akenji T. Epidemiological and clinical profile of paediatric malaria: a cross sectional study performed on febrile children in five epidemiological strata of malaria in Cameroon. BMC Inf Dis. 2017;17:499.

46. Atangana J, Bigoga J, Patchoke S, Ndjemai M, Tabue R, Nem T, et al. Anopheline fauna and malaria transmission in four ecologically distinct zones in Cameroon. Acta Trop. 2010;115:131-6. 
47. Barbazan P, Baldet T, Darriet F, Escaffre H, Djoda DH, Hougard JM. Impact of treatments with Bacillus sphaericus on Anopheles populations and the transmission of malaria in Maroua, a large city in a savannah region of Cameroon. J Am Mosq Control Assoc. 1998;14:33-9.

48. Atangana J, Fomena A, Tamesse JL, Fondjo E. Pratiques agricoles et épidémiologie du paludisme en zone soudano-sahélienne du Cameroun. Bull Soc Path Exot. 2012;105:23-9.

49. Robert V, Broek A, Stevens P, Slootweg R, Petrarca V, Coluzzi M. Mosquitoes and malaria transmission in irrigated rice-fields in the Benoue Valley of northern Cameroon. Acta Trop. 1992;52:201-4.

50. Antonio-Nkondjio C, Atangana J, Ndo C, Awono-Ambene P, Fondjo E, Fontenille D. Malaria transmission and rice cultivation in Lagdo, northern Cameroon. Trans R Soc Trop Med Hyg. 2008;102:52-359.

51. Kleinschmidt I, Bradley J, Knox TB, Mnzava AP, Kafy HT, Mbogo C. Implications of insecticide resistance for malaria vector control with longlasting insecticidal nets: a WHO-coordinated, prospective, international, observational cohort study. Lancet Infect Dis. 2018;18:640-9.

52. Tabue RN, Awono-Ambene P, Etang J, Atangana J, Antonio-Nkondjio C, Toto JC. Role of Anopheles (Cellia) rufipes (Gough, 1910) and other local anophelines in human malaria transmission in the northern savannah of Cameroon: a cross-sectional survey. Parasit Vectors. 2017;10:22.

53. Awono-Ambene PH, Etang J, Antonio-Nkondjio C, Ndo C, Eyisap WE, Piameu MC, et al. The bionomics of the malaria vector Anopheles rufipes Gough, 1910 and its susceptibility to deltamethrin insecticide in North Cameroon. Parasit Vectors. 2018;11:253.

54. HCR. https://data2.unhcr.org/en/country/cmr. Accessed 30 Aug 2019.

55. Raccurt C, Bourianne C, Lambert M, Tribouley J, Mandji O, Amadou A, et al. Malaria incidences, larval ecology and trophic activity of Anopheles mosquitoes in Djohong (Adamaoua, Cameroon) in the rainy season. Med Trop. 1993;53:355-62.

56. Domfang J. Etude de la transmission du paludisme dans la ville de Tibati (Adamaoua Cameroun). Yaoundé: Rapport OCEAC; 2006.

57. Ndo C, Kopya E, Menze-Djantio B, Toto JC, Awono-Ambene P, Lycett $G$, et al. High susceptibility of wild Anopheles funestus to infection with natural Plasmodium falciparum gametocytes using membrane feeding assays. Parasit Vectors. 2016;9:341.

58. Kwenti ET, Kwenti TDB, Njunda LA, Latz A, Nkuo-Akenji T. Epidemiological and clinical profile of paediatric malaria: a cross sectional study performed on febrile children in five epidemiological strata of malaria in Cameroon. BMC Infect Dis. 2017:17:499.

59. Menze BD, Wondji MJ, Tchapga W, Tchoupo M, Riveron JM, Wondji CS. Bionomics and insecticides resistance profiling of malaria vectors at a selected site for experimental hut trials in central Cameroon. Malar J. 2018;17:317.

60. Atangana S, Foumbi J, Charlois M, Ambroise-Thomas P, Ripert C. Epidemiological study of onchocerciasis and malaria in Bamendjin dam area (Cameroon). Malacologic fauna and risks of schistosomian introduction. Med Trop. 1979;39:537-43.

61. Tchuinkam T, Simard F, Lélé-Defo E, Téné-Fossog B, Tateng-Ngouateu A, Antonio-Nkondjio C. Bionomics of anopheline species and malaria transmission dynamics along an altitudinal transect in Western Cameroon. BMC Infect Dis. 2010;10:119.

62. Ndong IC, Reenen M, Boakye DA, Mbacham WF, Grobler AF. Trends in malaria admissions at the Mbakong health Centre of the North West Region of Cameroon: a retrospective study. Malar J. 2014;13:328.

63. Tabue R, Nem T, Atangana J, Bigoga J, Patchoke S, Tchouine F, et al. Anopheles ziemanni a locally important malaria vector in Ndop health district, north west region of Cameroon. Parasit Vectors. 2014;7:262.

64. Amvongo-Adjia N, Wirsiy EL, Riveron JM, Chounna Ndongmo WP, Enyong PA, Njiokou F, et al. Bionomics and vectorial role of anophelines in wetlands along the volcanic chain of Cameroon. Parasit Vectors. 2018;11:471.

65. Cornu M, Combe A, Couprie B, Moyou Somo R, Carteron B, Van Harten W, et al. Epidemiological aspects of malaria in 2 villages of the Manyemen forest region (Cameroon, Southwest province). Med Trop. 1986:46:131-40.

66. Van der Kolk M, Etti Tebo A, Nimpaye H, Ngo Ndombol D, Sauerwein R, Eling W. Transmission of Plasmodium falciparum in urban Yaoundé Cameroon is seasonal and age-dependent. Trans R Soc Trop Med Hyg. 2003:97:375-9.
67. Bigoga J, Manga L, Titanji V, Coetzee M, Leke R. Malaria vectors and transmission dynamics in coastal south-western Cameroon. Malar J. 2007:6:5.

68. Sumbele I, Ning T, Bopda O, Nkuo-Akenji T. Variation in malariometric and red cell indices in children in the Mount Cameroon area following enhanced malaria control measures: evidence from a repeated cross-sectional study. Malar J. 2014;13:334.

69. Quakyi I, Leke R, Befidi-Mengue R, Tsafack M, Bomba-Nkolo D, Manga $L$, et al. The epidemiology of Plasmodium falciparum malaria in two Cameroonian villages: Simbok and Etoa. Am J Trop Med Hyg. 2000;63:222-30.

70. Fru-Cho J, Anong D, Ayonghe S, Wanji S, Nkuo-Akenji T. The influence of seasonal variations on malaria prevalence in Mount Cameroon Region: a review. J Cameroon Acad Sci. 2013;11:11-5.

71. Achidi E, Apinjoh T, Anchang-Kimbi J, Mugri R, Ngwai A, Yafi C. Severe and uncomplicated falciparum malaria in children from three regions and three ethnic groups in Cameroon: prospective study. Malar J. 2012;11:215.

72. Apinjoh TO, Anchang-Kimbi JK, Mugri RN, Nyingchu RV, Tangoh DA, Chi HF. The effect of insecticide treated nets (ITNs) on Plasmodium falciparum infection in rural and semi-urban communities in the south westregion of Cameroon. PLoS ONE. 2015;10:e0116300

73. Sumbele IU, Kimbi HK, Ndamukong-Nyanga JL, Nweboh M, Anchang-Kimbi JK. Malarial anaemia and anaemia severity in apparently healthy primary school children in urban and rural settings in the Mount Cameroon area: cross sectional survey. PLOS ONE. 2015;10:e0123549.

74. Bate A, Kimbi HK, Lum E, Lehman LG, Onyoh EF, Ndip LM, et al. Malaria infection and anaemia in HIV-infected children in Mutengene, Southwest Cameroon: a cross sectional study. BMC Infect Dis. 2016;16:523

75. Yekabong RC, Ebile WA, Fon PN, Asongalem EA. The impact of mass distribution of long-lasting insecticide-treated bed-nets on the malaria parasite burden in the Buea Health District in South-West Cameroon: a hospital based chart review of patient's laboratory records. BMC Res Notes. 2017;10:534.

76. Teh RN, Sumbele IUN, Meduke DN, Ojong ST, Kimbi HK. Malaria parasitaemia, anaemia and malnutrition in children less than 15 years residing in different altitudes along the slope of Mount Cameroon: prevalence, intensity and risk factors. Malar J. 2018;17:336.

77. Nyasa RB, Zofou D, Kimbi HK, Kum KM, Ngu RC, Titanji VPK. The current status of malaria epidemiology in Bolifamba, atypical Cameroonian rainforest zone: an assessment of intervention strategies and seasonal variations. BMC Public Health. 2015;15:1105.

78. Mbu R, Takang W, Fouedjio H, Fouelifack F, Tumasang F, Tonye R. Clinical malaria among pregnant women on combined insecticide treated nets (ITNs) and intermittent preventive treatment (IPTp) with sulphadoxine-pyrimethamine in Yaounde, Cameroon. BMC Women's Health. 2014;14:68.

79. Leke RGF, Bigoga JD, Zhou J, Fouda GG, Leke RJ, Tchinda V. Longitudinal studies of Plasmodium falciparum malaria women living in a rural Cameroonian village with high perennial transmission. Am J Trop Med Hyg. 2010;83:996-1004.

80. Zeukeng F, Tchinda VHM, Bigoga JD, Seumen CHT, Ndzi ES, Abonweh G, et al. Co-infections of malaria and geohelminthiasis in two rural communities of Nkassomo and Vian in the Mfou Health District, Cameroon. PLoS Negl Trop Dis. 2014;8:e3236.

81. Achonduh-Atijegbe OA, Mfuh KO, Mbange AHE, Chedjou JP, Taylor DW, Nerurkar VR, et al. Prevalence of malaria, typhoid, toxoplasmosis and rubella among febrile children in Cameroon. BMC Infect Dis. 2016;16:658.

82. Wanji S, Tanke T, Atanga N, Ajonina C, Tendongfor N, Fontenille D. Anopheles species of the mount Cameroon region: biting habits, feeding behaviour ant entomological inoculation rates. Trop Med Int Health. 2003;8:643-9.

83. Le Goff G, Robert V, Fondjo E, Carnevale P. Efficacy of insecticide impregnated bednets to control malaria in a rural forested area in southern Cameroon. Mem Inst Oswaldo Cruz. 1992;87:355-9.

84. Carnevale P, Le Goff G, Toto J, Robert V. Anopheles nili as the main vector of human malaria in villages of southern Cameroon. Med Vet Entomol. 1992;6:135-8. 
85. Fondjo E, Robert V, Le Goff G, Toto J, Carnevale P. Urban malaria transmission in Yaounde (Cameroon). 2. Entomologic study in 2 semi urban districts. Bull Soc Path Exot. 1992;85:57-63.

86. Nimpaye H, Van Der Kolk M, Fontenille D, Boudin C. Le paludisme urbain à Yaoundé (Cameroun) en 2000. Etude entomologique dans le quartier central "Dakar". Bull Liais Doc OCEAC. 2001;34:11-4.

87. Antonio-Nkondjio C, Awono-Ambene H, Toto J, Meunier J, ZebazeKemleu S, Nyambam R. High malaria transmission intensity in suburban area of Yaoundé: the capital city of Cameroon. J Med Entomol. 2002;39:350-5.

88. Antonio-Nkondjio C, Simard F, Awono-Ambene P, Ngassam P, Toto J, Tchuinkam T. Malaria vectors and urbanization in the equatorial forest region of south Cameroon. Trans R Soc Trop Med Hyg. 2005;99:347-54.

89. Antonio-Nkondjio C, Demanou M, Etang J, Bouchite B. Impact of cyfluthrin (Solfac EW050) impregnated bed nets on malaria transmission in the city of Mbandjock: lessons for the nationwide distribution of long-lasting insecticidal nets (LLINs) in Cameroon. Parasit Vectors. 2013;6:10.

90. Awono-Ambene HP, Antonio Nkondjio C, Toto JC, Ndo C, Etang J, Fontenille D. Epidemiological importance of the Anopheles nili group of malaria vectors in equatorial villages of Cameroon, Central Africa. Sci Med Africa. 2009;1:13-20.

91. Cohuet A, Simard F, Wondji C, Antonio-Nkondjio C, Awono-Ambene $\mathrm{H}$, Fontenille D. High malaria transmission intensity due to Anopheles funestus (Diptera: Culicidae) in a village of Savannah-Forest transmission area in Cameroon. J Med Entomol. 2004;41:901-5.

92. Bigoga D, Nanfack F, Awono-Ambene P, Patchoke S, Atangana J, Otia $\checkmark$, et al. Seasonal prevalence of malaria vectors and entomological inoculation rates in the rubber cultivated area of Niete, South Region of Cameroon. Parasit Vectors. 2012;5:197.

93. Antonio-Nkondjio C, Defo-Talom B, Tagne-Fotso R, Tene-Fossog B, Ndo C, Lehman L. High mosquito burden and malaria transmission in a district of the city of Douala, Cameroon. BMC Infect Dis. 2012;12:275.

94. Ntonga Akono P, Tonga C, Mbida Mbida J, Ngo Hondt O, AwonoAmbene $\mathrm{H}, \mathrm{Ndo} \mathrm{C}$. Anopheles gambiae, vecteur majeur du paludisme à Logbessou, zone péri-urbaine de Douala (Cameroun). Bull Soc Pathol Exot. 2015;108:360-8.

95. Ndo C, Kopya E, Donbou MA, Njiokou F, Awono-Ambene P, Wondji C. Elevated Plasmodium infection rates and high pyrethroid resistance in major malaria vectors in a forested area of Cameroon highlight challenges of malaria control. Parasit Vectors. 2018;11:157.

96. Antonio-Nkondjio C, Tene Fossog B, Kopya E, Poumachu Y, Menze Djantio B, Ndo C. Rapid evolution of pyrethroid resistance prevalence in Anopheles gambiae populations from the cities of Douala and Yaounde (Cameroon). Malar J. 2015;14:155.

97. Keiser J, Caldas de Castro M, Maltese M, Bos R, Tanner M, Sanger B, et al. The effect of irrigation and large dams on the burden of malaria on global and regional scale. Am J Trop Med Hyg. 2004;72:392-406.

98. Wang $L$, Jaal Z. Sublethal effects of Bacillus thuringiensis $\mathrm{H}-14$ on the survival rate, longevity, fecundity and F1 generation developmental period of Aedes aegypti. Dengue Bull. 2005;29:192-6.

99. Antonio-Nkondjio C, Fossog B, Ndo C, Djantio B, Togouet S, AwonoAmbene P. Anopheles gambiae distribution and insecticide resistance in the cities of Douala and Yaounde (Cameroon): influence of urban agriculture and pollution. Malar J. 2011;10:154.

100. Tene Fossog B, Kopya E, Ndo C, Menze-Djantio B, Costantini C, Njiokou F. Water quality and Anopheles gambiae larval tolerance to pyrethroids in the cities of Douala and Yaounde (Cameroon). J Trop Med. 2012;2012:429817.

101. Doumbe-Belisse P, Ngadjeu C, Sonhafouo-Chiana N, Talipouo A Djamouko-Djonkam L, Kopya E, et al. High malaria transmission sustained by Anopheles gambiae s.l. occurring both indoors and outdoors in the city of Yaoundé, Cameroon. Wellcome Open Res. 2018;3:164.

102. Pankoui-Mfonkeu J, Gouado I, Fotso-Kuate H, Zambou O, Grau G, Combes V, et al. Clinical presentation, haematological indices and management of children with severe and uncomplicated malaria in Douala, Cameroon. Pak J Biol Sci. 2008;11:2401-6.

103. Roman DNR, Rosalie NNA, Kumar A, Luther KMM, Singh V, Albert MS. Asymptomatic Plasmodium malariae infections in children from suburban areas of Yaoundé, Cameroon. Parasitol Int. 2018;67:29-33.
104. Kwenti ET, Kwenti TDB, Njunda LA, Latz A, Nkuo-Akenji T. Identification of the Plasmodium species in clinical isolates from children residing in five epidemiological strata of malaria in Cameroon. Trop Med Health. 2017;45:14.

105. Sandeu MM, Bayibéki AN, Tchioffo MT, Abate L, Gimonneau G, AwonoAmbéné PH, et al. Do the venous blood samples replicate malaria parasite densities found in capillary blood? A field study performed in naturally-infected asymptomatic children in Cameroon. Malar J. 2017; 16:345.

106. Sundararaman SA, Liu W, Keele BF, Learn GH, Bittinger K, Mouacha F. Plasmodium falciparum-like parasites infecting wild apes in southern Cameroon do not represent a recurrent source of human malaria. Proc Natl Acad Sci USA. 2013;110:7020-5.

107. Annan Z, Durand P, Ayala FJ, Arnathau C, Awono-Ambene P, Simard F, et al. Population genetic structure of Plasmodium falciparum in the two main African vectors, Anopheles gambiae and Anopheles funestus. Proc Natl Acad Sci USA. 2007;104:7987-92.

108. Morlais I, Nsango SE, Toussile W, Abate L, Annan Z, Tchioffo MT, et al. Plasmodium falciparum mating patterns and mosquito infectivity of natural isolates of gametocytes. PLoS ONE. 2015;10:e0123777.

109. Rubio J, Benito A, Roche J, Berzosa P, Garcia M, Mico M, et al. Seminested, multiplex polymerase chain reaction for detection of human malaria parasites and evidence of Plasmodium vivax infection in Equatorial Guinea. Am J Trop Med Hyg. 1999;60:183-7.

110. Mendes C, Dias F, Figueiredo J, Mora V, Cano J, de Sousa B, et al. Duffy negative antigen is no longer a barrier to Plasmodium vivax - molecular evidences from the African west coast (Angola and Equatorial Guinea). PLoS Negl Trop Dis. 2011;5:e1192.

111. Baird JK, Maguire JD, Price RN. Diagnosis and treatment of Plasmodium vivax malaria. Adv Parasitol. 2012;80:203-70.

112. Baird JK, Battle KE, Howes RE. Primaquine ineligibility in anti-relapse therapy of Plasmodium vivax malaria: the problem of G6PD deficiency and cytochrome P-450 2D6 polymorphisms. Malar J. 2018;17:42.

113. Bardaji A, Martinez-Espinosa FE, Arevalo-Herrera M, Padilla N, Kochar S, Ome-Kaius M. Burden and impact of Plasmodium vivax in pregnancy: a multi-centre prospective observational study. PLoS Negl Trop Dis. 2017;11:e0005606.

114. Liu W, LiY, Shaw KS, Learn GH, Plenderleith LJ, Malenke JA. African origin of the malaria parasite Plasmodium vivax. Nat Commun. 2014;5:3346.

115. Liu W, Li Y, Learn GH, Rudicell RS, Robertson JD, Keele BF. Origin of the human malaria parasite Plasmodium falciparum in gorillas. Nature. 2010;467:420-5.

116. Boundenga L, Ollomo B, Rougeron V, Mouele LY, Mve-Ondo B, DelicatLoembet LM, et al. Diversity of malaria parasites in great apes in Gabon. Malar J. 2015;14:111.

117. Prugnolle F, Ollomo B, Durand P, Yalcindag E, Arnathau C, Elguero E, et al. African monkeys are infected by Plasmodium falciparum nonhuman primate-specific strains. Proc Natl Acad Sci USA. 2011;108:11948-53.

118. Paupy C, Makanga B, Ollomo B, Rahola N, Durand P, Magnus J, et al. Anopheles moucheti and Anopheles vinckei are candidate vectors of ape Plasmodium parasites, including Plasmodium praefalciparum in Gabon. PLOS ONE. 2013:8:e57294.

119. Singh B, Kim Sung L, Matusop A, Radhakrishnan A, Shamsul S, CoxSingh J, et al. A large focus of naturally acquired Plasmodium knowlesi infections in human beings. Lancet. 2004;263:1017-24.

120. William T, Jelip J, Menon J, Anderios F, Mohammad R, Awang Mohammad TA, et al. Changing epidemiology of malaria in Sabah, Malaysia: increasing incidence of Plasmodium knowlesi. Malar J. 2014;13:390.

121. Yong A, Navaratnam P, Kadirvelu A, Pillai N, Pillai N. Re-emergence of malaria in Malaysia: a review article. OALibJ. 2018;5:1-16.

122. World Health Organization. Global malaria programme world malaria report 2013. Geneva: World Health Organization; 2013.

123. William T, Rahman H, Jelip J, Ibrahim M, Menon J, Grigg M, et al. Increasing incidence of Plasmodium knowlesi malaria following control of $P$. falciparum and P. vivax malaria in Sabah, Malaysia. PLoS Negl Trop Dis. 2013;7:e2026

124. Basco L, Ngane V, Ndounga M, Same-Ekobo A, Youmba J, Abodo $\mathrm{R}$, et al. Molecular epidemiology of malaria in Cameroon. XXI. Baseline therapeutic efficacy of chloroquine, amodiaquine, and 
sulfadoxine-pyrimethamine monotherapies in children before national drug policy change. Am J Trop Med Hyg. 2006;75:388-95.

125. PSI. https://www.psi.org/wp-content/uploads/2014/10/iCCM_Mid_ Term_Results_Cameroun.pdf. Accessed 30 Aug 2019.

126. Bekolo CE, Williams TDA. Adding proactive and reactive case detection into the integrated community case management system to optimise diagnosis and treatment of malaria in a high transmission setting of Cameroon: an observational quality improvement study. BMJ Open. 2019:9:e026678.

127. Collins D, Jarrah Z, Gilmartin C, Saya U. The costs of integrated community case management (iCCM) programs: a multi-country analysis. J Glob Health. 2014:4:020407.

128. Whegang SY, Tahar R, Foumane VN, Soula G, Gwet H, Thalabard JC. Efficacy of non-artemisinin- and artemisinin-based combination therapies for uncomplicated falciparum malaria in Cameroon. Malar J. 2010;9:56.

129. Whegang Youdom S, Chiabi A, Basco LK. Monitoring the efficacy and safety of artemisinin-based combination therapies: a review and network meta-analysis of antimalarial therapeutic efficacy trials in Cameroon. Drugs R D. 2019;19:1-14.

130. Tietche F, Chelo D, Mina Ntoto N, Djoukoue F, Hatz C, Frey S, et al. Tolerability and efficacy of a pediatric granule formulation of artesunatemefloquine in young children from Cameroon with uncomplicated falciparum malaria. Am J Top Med Hyg. 2010;82:1034-40.

131. Nji AM, Ali IM, Moyeh MN, Ngongang E-O, Ekollo AM, Chedjou J-P, et al. Randomized non-inferiority and safety trial of dihydroartemisin-piperaquine and artesunate-amodiaquine versus artemether-lumefantrine in the treatment of uncomplicated Plasmodium falciparum malaria in Cameroonian children. Malar J. 2015;14:27.

132. Burchett HED, Leurent B, Baiden F, Baltzell K, Björkman A, Bruxvoort K, et al. Improving prescribing practices with rapid diagnostic tests (RDTs): synthesis of 10 studies to explore reasons for variation in malaria RDT uptake and adherence. BMJ Open. 2017;7:e012973.

133. Fokam EB, Dzi KTJ, Ngimuh L, Enyong P. The effect of long lasting insecticide bed net use on malaria prevalence in the Tombel Health District, South West Region-Cameroon. Malar Res Treat. 2016;2016:3216017.

134. Maka DE, Chiabi A, Ndikum V, Achu D, Mah E, Nguefack S, et al. A randomized trial of the efficacy of artesunate and three quinine regimens in the treatment of severe malaria in children at the Ebolowa Regional Hospital, Cameroon. Malar J. 2015;14:429.

135. Reuters. https://www.reuters.com/article/us-westafrica-drugs-fake/ tens-of-thousands-die-in-africa-each-year-due-to-fake-drugs-idUSK CN1NK23I. Accessed 30 Aug 2019

136. Talipouo A, Ngadjeu CS, Doumbe-Belisse P, Djamouko-Djonkam L, Sonhafouo-Chiana N, Kopya E, et al. Malaria prevention in the city of Yaoundé: knowledge and practices of urban dwellers. Malar J. 2019:18:167.

137. Ndo C, Menze-Djantio B, Antonio-Nkondjio C. Awareness, attitudes and prevention of malaria in the cities of Douala and Yaoudé (Cameroon). Parasit Vectors. 2011:4:181.

138. Reuters health news Tens of thousands die each year in Africa due to fake drugs. https://www.reuters.com/article/us-westafrica-drugs-fake/ tens-of-thousands-die-in-africa-each-year-due-to-fake-drugs-idUSK CN1NK23I. Accessed 15 Nov 2018.

139. Djimde A, Doumbo O, Cortese J, Kayentao K, Doumbo S, Diourte Y, et al. A molecular marker for chloroquine-resistant falciparum malaria. N Engl J Med. 2001;344:257-63.

140. Sa J, Twu O, Hayton K, Reyes S, Fay M, Ringwald P, et al. Geographic patterns of Plasmodium falciparum drug resistance distinguished by differential responses to amodiaquine and chloroquine. Proc Natl Acad Sci USA. 2009:106:18883-9.

141. Sidhu A, Verdier-Pinard D, Fidock D. Chloroquine resistance in Plasmodium falciparum malaria parasites conferred by pfcrt mutations. Science. 2002;298:210-3.

142. Cheruiyot J, Ingasia LA, Omondi AA, Juma DW, Opot BH, Ndegwa JM. Polymorphisms in Pfmdr1, Pfcrt, and Pfnhel genes are associated with reduced in vitro activities of quinine in Plasmodium falciparum isolates from western Kenya. Antimicrob Agents Chemother. 2014;58:3737-43.

143. Ursing J, Kofoed PE, Rodrigues A, Rombo L, Gil JP. Plasmodium falciparum genotypes associated with chloroquine and amodiaquine resistance in Guinea-Bissau. Am J Trop Med Hyg. 2007;76:844-8.
144. Dorsey G, Kamya MR, Singh A, Rosenthal PJ. Polymorphisms in the Plasmodium falciparum pfcrt and pfmdr-1 genes and clinical response tochloroquine in Kampala. Uganda J Infect Dis. 2001;183:1417-20.

145. Sisowath C, Ferreira P, Bustamante L, Dahlstrom S, Martensson A, Bjorkman $A$, et al. The role of pfmdr1 in Plasmodium falciparum tolerance to artemether-lumefantrine in Africa. Trop Med Int Health. 2007;12:736-42.

146. Smith SJ, Kamara ARY, Sahr F, Samai M, Swaray AS, Menard D, et al. Efficacy of artemisinin-based combination therapies and prevalence of molecular markers associated with artemisinin, piperaquine and sulfadoxine-pyrimethamine resistance in Sierra Leone. Acta Trop. 2018;185:363-70

147. Chauvin P, Menard S, Iriart X, Nsango SE, Tchioffo MT, Abate L. Prevalence of Plasmodium falciparum parasites resistant to sulfadoxine/ pyrimethamine in pregnant women in Yaoundé, Cameroon: emergence of highly resistant pfdhfr/pfdhps alleles. J Antimicrob Chemother. 2015;70:2566-71.

148. Ali IM, Netongo PM, Atogho-Tiedeu B, Ngongang EO, Ajua A, Achidi EA. Amodiaquine-artesunate versus artemether-lumefantrine against uncomplicated malaria in children less than 14 years in Ngaoundere, North Cameroon: efficacy, safety, and baseline drug resistant mutations in pfcrt, pfmdr1, and pfdhfr genes. Malar Res Treat. 2013;2013:234683.

149. Mbacham W, Evehe M, Netongo P, Ateh I, Mimche P, Ajua A, et al. Efficacy of amodiaquine, sulphadoxine-pyrimethamine and their combination for the treatment of uncomplicated Plasmodium falciparum malaria in children in Cameroon at the time of policy change to artemisininbased combination therapy. Malar J. 2010;9:34.

150. Ali IM, Evehe MSB, Netongo PM, Atogho-Tiedeu B, Akindeh-Nji M, $\mathrm{Ngora} \mathrm{H}$, et al. Host candidate gene polymorphisms and associated clearance of $P$. falciparum amodiaquine and fansidar resistance mutants in children less than 5 years in Cameroon. Pathog Glob Health. 2014:108:323-33.

151. Menard S, Morlais I, Tahar R, Sayang C, Mayengue PI, Iriart X, BenoitVical F, Lemen B, Magnaval JF, Awono-Ambene P, Basco LK, Berry A. Molecular monitoring of Plasmodium falciparum drug susceptibility at the time of the introduction of artemisinin based combination therapy in Yaounde, Cameroon: implications for the future. Malar J. 2012;11:113.

152. Mbenda HGN, Das A. Occurrence of multiple chloroquine-resistant Pfcrt haplotypes and emergence of the S(agt)VMNT type in Cameroonian Plasmodium falciparum. J Antimicrob Chemother. 2014;69:400-3.

153. Ndam NT, Basco LK, Ngane VF, Ayouba A, Ngolle EM, Deloron P, et al. Reemergence of chloroquine-sensitive pfcrt K76 Plasmodium falciparum genotype in southeastern Cameroon. Malar J. 2017:16:130.

154. Ngassa Mbenda HG, Das A. Analysis of genetic diversity in the chloroquine-resistant gene Pfcrt in field Plasmodium falciparum isolates from five regions of the southern Cameroon. Infect Genet Evol. 2016:44:450-8

155. Ménard D, Khim N, Beghain J, Adegnika AA, Shafiul-Alam M, Amodu O. A Worldwide map of Plasmodium falciparum K13-propeller polymorphisms. N Engl J Med. 2016;374:2453-64.

156. Djaman J, Olefongo D, Ako A, Roman J, Ngane V, Basco LK, et al. Molecular epidemiology of malaria in Cameroon and Côte d'Ivoire. XXXI. Kelch 13 propeller sequences in Plasmodium falciparum isolates before and after implementation of artemisinin-based combination therapy. Am J Top Med Hyg. 2017;97:222-4.

157. Minusca. https://peacekeeping.un.org/en/mission/minusca. Accessed 30 Aug 2019

158. Wondji C, Frederic S, Petrarca V, Etang J, Santolamazza F, Della TA. Species and populations of the Anopheles gambiae complex in Cameroon with special emphasis on chromosomal and molecular forms of Anopheles gambiae s.s. J Med Entomol. 2005;42:998-1005.

159. Antonio-Nkondjio C, Ndo C, Costantini C, Awono-Ambene H, Fontenille D. Simard F. Distribution and larval habitat characterization of Anopheles nili and A. moucheti along river networks in south Cameroon. Acta Trop. 2009:112:270-6.

160. Ayala D, Carlo C, Ose K, Kamdem G, Antonio-Nkondjio C, Agbor J. Habitat suitability and ecological niche profile of major malaria vectors in Cameroon. Malar J. 2009;8:307.

161. Simard F, Ayala D, Kamdem G, Pombi M, Etouna J, Ose K. Ecological niche partitioning between Anopheles gambiae molecular forms in Cameroon: the ecological side of speciation. BMC Ecol. 2009:9:17. 
162. Russell T, Govella N, Azizi S, Drakeley C, Kachur S, Killeen G. Increased proportions of outdoor feeding among residual malaria vector populations following increased use of insecticide-treated nets in rural Tanzania. Malar J. 2011;10:80.

163. Kitau J, Oxborough R, Tungu P, Matowo J, Malima R, Magesa S, et al. Species shifts in the Anopheles gambiae complex: do LLINs successfully control Anopheles arabiensis? PLoS ONE. 2012;7:e31481.

164. Bamou R, Mbakop LR, Kopya E, Ndo C, Awono-Ambene P, Tchuinkam T, et al. Changes in malaria vector bionomics and transmission patterns in the equatorial forest region of Cameroon between 2000 and 2017. Parasit Vectors. 2018;11:464.

165. Antonio-Nkondjio C, Meunier J, Awono-Ambene H, Fontenille D. La présence de bovins comme hôte alternatifs peut elle modifier le comportement trophique des vecteurs du paludisme en zone de forêt ? Sci Med Afr. 2009;1:7-12.

166. Antonio-Nkondjio C, Atangana J, Ndo C, Awono-Ambene P, Fondjo E, Fontenille D, et al. Malaria transmission and rice cultivation in Lagdo, northern Cameroon. Trans R Soc Trop Med Hyg. 2008;102:352-9.

167. Antonio-Nkondjio C, Sonhafouo-Chiana N, Ngadjeu CS, DoumbeBelisse P, Talipouo A, Djamouko-Djonkam L. Review of the evolution of insecticide resistance in main malaria vectors in Cameroon from 1990 to 2017. Parasit Vectors. 2017;10:472.

168. Müller GC, Kravchenko VD, Schlein Y. Decline of Anopheles sergentii and Aedes caspius populations following presentation of attractive toxic (spinosad) sugar bait stations in an oasis. J Am Mosq Control Assoc. 2008;24:147-9.

169. Chouaibou M, Etang J, Brevault T, Nwane P, Hinzoumbe C, Mimpfoundi R. Dynamics of insecticide resistance in the malaria vector Anopheles gambiae s.l. from an area of extensive cotton cultivation in northern Cameroon. Trop Med Int Health. 2008;13:476-86.

170. Overgaard H, Saebo S, Reddy M, Reddy V, Abaga S, Matias A, et al. Light traps fail to estimate reliable malaria mosquito biting rates on Bioko Island, Equatorial Guinea. Malar J. 2012;11:56.

171. Tene Fossog B, Ayala D, Acevedo P, Kengne P, Ngomo Abeso Mebuy I, Makanga B. Habitat segregation and ecological character displacement in cryptic African malaria mosquitoes. Evol Appl. 2015;8:326-45.

172. Pombi M, Kengne P, Gimonneau G, Tene-Fossog B, Ayala D, Kamdem $\mathrm{C}$, et al. Dissecting functional components of reproductive isolation among closely related sympatric species of the Anopheles gambiae complex. Evol Appl. 2017;10:1102-20.

173. Kamdem C, Fossog BT, Simard F, Etouna J, Ndo C, Kengne P, et al. Anthropogenic habitat disturbance and ecological divergence between incipient species of the malaria mosquito Anopheles gambiae. PLOS ONE. 2012;7:e39453.

174. Boissiere A, Gimonneau G, Tchioffo M, Abate L, Bayibeki A, AwonoAmbene $\mathrm{P}$, et al. Application of a qPCR assay in the investigation of susceptibility to malaria infection of the $\mathrm{M}$ and $\mathrm{S}$ molecular forms of $A n$. gambiae s.s. in Cameroon. PLoS ONE. 2013;8:e54820.

175. Mbida AM, Etang J, Akono N, Talipouo A, Awono-Ambene P, Oke-Agbo $F$, et al. Preliminary investigation on aggressive culicidae fauna and malaria transmission in two wetlands of the Wouri river estuary, LittoralCameroon. J Entomol Zool Stud. 2016;4:6.

176. Klinkenberg E, McCall P, Wilson M, Amerasinghe F, Donnelly M. Impact of urban agriculture on malaria vectors in Accra, Ghana. Malar J. 2008;7:151.

177. Wang S, Lengeler C, Smith T, Vounatsou P, Cisse G, Diallo D, et al. Rapid urban malaria appraisal (RUMA) in sub-Saharan Africa. Malar J. 2005:4:40

178. Keiser J, Utzinger J, Caldas Castro M, Smith TA, Tanner M, Singer BH. Urbanization in sub-Saharan Africa and implication for malaria control. Am J Trop Med Hyg. 2004;71:118-27

179. Cohuet A, Simard F, Toto J, Kengne P, Coetzee M. Species identification within the Anopheles funestus group of malaria vectors in Cameroon and evidence for a new species. Am J Trop Med Hyg. 2003;69:200-5.

180. Mouatcho J, Cornel AJ, Dahan-Moss Y, Koekemoer LL, Coetzee M, Braack L. Detection of Anopheles rivulorum-like, a member of the Anopheles funestus group, in South Africa. Malar J. 2018;17:195.

181. Koekemoer L, Kamau L, Hunt R, Coetzee M. A cocktail polymerase chain reaction assay to identify members of the Anopheles funestus (Diptera: Culicidae) group. Am J Trop Med Hyg. 2002;66:804-11.
182. Dia I, Lochouarn L, Boccolini D, Costantini C, Fontenille D. Spatial and temporal variations of the chromosomal inversion polymorphism of Anopheles funestus in Senegal. Parasite. 2000;7:179-84.

183. Awono-Ambene P, Antonio-Nkondjio C, Toto J, Ndo C, Etang J, Fonte-

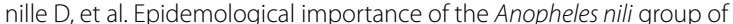
malaria vectors in equatorial villages of Cameroon, Central Africa. Sci Med Afr. 2009:1:13-20.

184. Fontenille D, Cohuet A, Awono-Ambene P, Antonio-Nkondjio C, Wondji $C$, Kengne $P$, et al. Systématique et biologie des Anophèles vecteurs de Plasmodium en Afrique, données récentes. Med Trop. 2003;63:247.

185. Cohuet A, Dia I, Simard F, Raymond M, Rousset F, Antonio-Nkondjio C, et al. Gene flow between chromosomal forms of the malaria vector Anopheles funestus in Cameroon Central Africa, and its relevance in malaria fighting. Genetics. 2005;169:301-11.

186. Ayala D, Caro-Riaño H, Dujardin J-P, Rahola N, Simard F, Fontenille D. Chromosomal and environmental determinants of morphometric variation in natural populations of the malaria vector Anopheles funestus in Cameroon. Infect Genet Evol. 2011:11:940-7.

187. Ayala D, Acevedo P, Pombi M, Dia I, Boccolini D, Costantini C, et al. Chromosome inversions and ecological plasticity in the main African malaria mosquitoes. Evolution. 2017;71:686-701.

188. Kamdem C, Fouet C, White BJ. Chromosome arm-specific patterns of polymorphism associated with chromosomal inversions in the major African malaria vector, Anopheles funestus. Mol Ecol. 2017;2:5552-66.

189. Wondji CS, Dabire RK, Tukur Z, Irving H, Djouaka R, Morgan JC. Identification and distribution of a GABA receptor mutation conferring dieldrin resistance in the malaria vector Anopheles funestus in Africa. Insect Biochem Mol Biol. 2011;41:484-91.

190. Wondji C, Irving H, Morgan J, Lobo N, Collins F, Hunt R. Two duplicated P450 genes are associated with pyrethroid resistance in Anopheles funestus, a major malaria vector. Genome Res. 2009;19:452-9.

191. Ibrahim SS, Riveron JM, Bibby J, Irving H, Yunta C, Paine MJ, et al. Allelic variation of cytochrome $\mathrm{P} 450$ s drives resistance to bednet insecticides in a major malaria vector. PLoS Genet. 2015;11:e1005618.

192. Ibrahim SS, Riveron JM, Stott R, Irving H, Wondji CS. The cytochrome P450 CYP6P4 is responsible for the high pyrethroid resistance in knockdown resistance-free Anopheles arabiensis. Insect Biochem Mol Biol. 2016:68:23-32

193. Irving H, Riveron J, Ibrahim S, Lobo N, Wondji C. Positional cloning of rp2 QTL associates the P450 genes CYP6Z1, CYP6Z3 and CYP6M7 with pyrethroid resistance in the malaria vector Anopheles funestus. Heredity. 2012:109:383-92.

194. Menze BD, Riveron JM, Ibrahim SS, Irving H, Antonio-Nkondjio C, Awono-Ambene PH. Multiple insecticide resistance in the malaria vector Anopheles funestus from northern Cameroon is mediated by metabolic resistance alongside potential target site insensitivity mutations. PLOS ONE. 2016;11:e0163261.

195. Riveron J, Irving H, Ndula M, Barnes K, Ibrahim S, Paine M. Directionally selected cytochrome $\mathrm{P} 450$ alleles are driving the spread of pyrethroid resistance in the major malaria vector Anopheles funestus. Proc Natl Acad Sci USA. 2013:110:252-7.

196. Riveron JM, Chiumia M, Menze BD, Barnes KG, Irving H, Ibrahim SS. Rise of multiple insecticide resistance in Anopheles funestus in Malawi: a major concern for malaria vector control. Malar J. 2015;14:344.

197. Riveron JM, Watsenga F, Irving H, Irish SR, Wondji CS. High Plasmodium infection rate and reduced bed net efficacy in multiple insecticideresistant malaria vectors in Kinshasa, Democratic Republic of Congo. $J$ Infect Dis. 2018;217:320-8.

198. Awono-Ambene H, Simard F, Antonio-Nkondjio C, Cohuet A, Kengne P. Fontenille D. Multilocus enzyme electrophoresis supports speciation within the Anopheles nili group of malaria vectors in Cameroon. Am J Trop Med Hyg. 2006;75:656-8.

199. Antonio Nkondjio C, Simard F. Highlights on Anopheles nili and Anopheles moucheti, malaria vectors in Africa. In: Manguin S, editor. Anopheles mosquitoes: new insights into malaria vectors. Rijeka: InTech; 2013. p. $221-38$.

200. Berthomieu A, Kengne P, Awono-Ambene H, Raymond M, Fontenille D, Weill M. Isolation and characterization of microsatellite DNA markers in the malaria vector Anopheles nili. Mol Ecol Notes. 2003;3:392-3.

201. Sharakhova M, Antonio-Nkondjio C, Xia A, Ndo C, Awono-Ambene $H$, Simard F, et al. Cytogenetic map for Anopheles nili: application for 
population genetics and comparative physical mapping. Infect Genet Evol. 2010;11:746-54.

202. Peery A, Sharakhova M, Antonio-Nkondjio C, Ndo C, Weill M, Simard F, et al. Improving the population genetics toolbox for the study of the African malaria vector Anopheles nili: microsatellite mapping to chromosomes. Parasit Vectors. 2011;4:202.

203. Fouet C, Kamdem C, Gamez S, White BJ. Genomic insights into adaptive divergence and speciation among malaria vectors of the Anopheles nili group. Evol Appl. 2017:10:897-906.

204. Ndo C, Simard F, Kengne P, Awono-Ambene P, Morlais I, Sharakhov I, et al. Cryptic genetic diversity within the Anopheles nili group of malaria vectors in the equatorial forest area of Cameroon (Central Africa). PLoS ONE. 2013;8:e58862

205. Ndo C, Antonio-Nkondjio C, Cohuet A, Ayala D, Kengne P, Morlais I, et al. Population genetic structure of the malaria vector Anopheles nili in subSaharan Africa. Malar J. 2010;9:161.

206. Gillies M, Coetzee M. A supplement to the Anophelinae of Africa south of the Sahara (Afrotropical region). Publ South Afr Inst Med Res. 1987;55:143

207. Gillies M, De Meillon B. The anophelinae of Africa South of the Sahara (Ethiopian Zoogeographical Region). Pub South Afr Inst Med Res. 1968:54:1-343.

208. Kengne P, Antonio-Nkondjio C, Awono-Ambene H, Simard F, Awolola T, Fontenille D. Molecular differentiation of three closely related members of the mosquito species complex Anopheles moucheti, by mitochondrial and ribosomal DNA polymorphism. Med Vet Entomol. 2007:21:177-82.

209. Njan Nloga A, Robert V, Toto J, Carnevale P. Anopheles moucheti, vecteur principal du paludisme au sud-Cameroun. Bull Liais Doc OCEAC. 1993;26:63-7.

210. Antonio-Nkondjio C, Ndo C, Kengne P, Mukwaya L, Awono-Ambene H, Fontenille $\mathrm{D}$, et al. Population structure of the malaria vector Anopheles moucheti in the equatorial forest region of Africa. Malar J. 2008;7:120.

211. Fouet C, Kamdem C, Gamez S, White BJ. Extensive genetic diversity among populations of the malaria mosquito Anopheles moucheti revealed by population genomics. Infect Genet Evol. 2017;48:27-33.

212. Sharakhova MV, Antonio-Nkondjio C, Xia A, Ndo C, Awono-Ambene $\mathrm{P}$, Simard F, et al. Polymorphic chromosomal inversions in Anopheles moucheti, a major malaria vector in Central Africa. Med Vet Entomol. 2014:28:337-40.

213. Nzogué J. Hygiène et ville coloniale au Cameroun français (1916-1960): enjeux et paradoxes d'une acculturation. http://etudescoloniales.canal blog.com/archives/2013/04/13/26915937.html. Etudes Coloniales. Accessed 11 Apr 2013

214. La Nzogué J. santé publique au Cameroun sous administration française, 1916-1957 Thèse de Doctorat/PhD en Histoire. Yaoundé: Université de Yaoundé; 2010.

215. Martin G. L'existence au Cameroun. Etudes sociales, études médicales, études d'hygiène et de prophylaxie. Paris: Emile Larose; 1921. p. 434-5.

216. Livadas G, Mouchet J, Chastang R. Peut-on envisager l'eradication du paludisme dans la region forestiere du Sud Cameroun? Riv Malariol. 1958:37:228-56

217. Cavalie P, Mouchet J. Les campagnes experimentales d'eradication du paludisme dans le Nord de la Republique du Cameroun. Med Trop. 1962:22:95-118.

218. Carnevale P, Mouchet J. La lutte antivectorielle au Cameroun. PasséPrésent-Avenir. Réflexions. Bull Soc Pathol Exot. 2001:94:202-9.

219. Mouchet J, Cavalie P, Callies J, Marticou H. Lirritabilite vis a vis du DDT d'Anopheles gambiae et d'A. funestus dans le Nord-Cameroun. Riv Malariol. 1961:40:191-217.

220. Molineaux L, Gramiccia G. The Garki Project. Research on the epidemiology and control of malaria in the Sudan Savanna of West Africa. Geneva: World Health Organization; 1980.

221. Molineaux L. The epidemiology of human malaria as an explanation for its distribution, including some implications for its control. In: Werndorfer WH, McGregor I, editors. Malaria: principles and practice of malariology. Edingburgh: Churchill Livingstone; 1988. p. 913-98.

222. Hamon J, Mouchet J, Brengues J, Chauvet G. Problems facing Anopheline vector control. Vector ecology and behaviour before, during, and after application of control measures. Misc Publ Entomol Soc Am. 1970;7:28-44.
223. Hamon J, Mouchet J, Chauvet G, Lumaret R. Bilan de quatorze années de lutte contre le paludisme dans les pays francophones d'Afrique et à Madagascar. Considérations sur la persistance de la transmission et perspectives d'avenir. Bull Soc Path Exot. 1963;56:971-93.

224. WHO. Stratégie mondiale de lutte antipaludique. 1. Paludisme - prévention \& contrôle. Geneva: World Health Organization; 1994

225. Payne D. Spread of chloroquine resistance in Plasmodium falciparum. Parasitol Today. 1987;3:241-6.

226. Sansonetti P, Bras J, Verdier F, Charmot G, Dupont B, Lapresle C. Chloroquine-resistant Plasmodium falciparum in Cameroon. Lancet. 1985;1:1154-5.

227. Ringwald P, Same-Ekobo A, Keundjian A, Kedy-Mangamba D, Basco LK. Chemoresistance of Plasmodium falciparum in urban areas of Yaounde, Cameroon. Part 1: surveillance of in vitro and in vivo resistance of Plasmodium falciparum to chloroquine from 1994 to 1999 in Yaounde, Cameroon. Trop Med Int Health. 2000;5:612-9.

228. Basco L. Molecular epidemiology of malaria in Cameroon. XIII. Analysis of pfcrt mutations and in vitro chloroquine resistance. Am J Trop Med Hyg. 2002;67:388-91.

229. Moyou-Somo R, Essomba P, Songue E, Tchoubou N, Ntambo A, Hiol $\mathrm{H}$, et al. A public private partnership to fight against malaria along the Chad-Cameroon pipeline corridor: I. Baseline data on socio-anthropological aspects, knowledge, attitudes and practices of the population concerning malaria. BMC Public Health. 2013;13:1023.

230. Robert V, le Goff G, Toto J, Mulder B, Fondjo E, Manga L, et al. Anthropophilic mosquitoes and malaria trnsmission at Edéa, Cameroon. Trop Med Parasitol. 1993:44:14-8.

231. Bouchite B, Baldet T, Demanou M, Antonio Nkondjio C, Folefack G. Essais de lutte opérationnelle contre le paludisme par l'utilisation de moustiquires imprégnées à l'échelle d'une agglomération agroindustrielle de tille moyenne du Sud Cameroun Mbandjock. Yaoundé: Rapport ORSTOM/CPC; 1998.

232. Programme National de Lutte contre le Paludisme-Cameroun. Plan Strategique National de Lutte contre le Paludisme au Cameroun, 2007-2010. Yaoundé: Rapport Ministère Santé Publique Cameroun; 2007.

233. Programme National de Lutte contre le Paludisme-Cameroun. Profil entomologique du paludisme au Cameroun. Yaoundé: Ministère de la Santé Publique; 2007.

234. Programme national de lutte contre le paludisme-Cameroun. Rapport de lutte contre le paludisme 2014. Yaoundé: Ministère de la Santé Publique; 2015

235. PNLP. Rapport d'activités du programme national contre le paludisme. Yaoundé: Ministère de la Santé Publique du Cameroun; 2015.

236. Bowen H. Impact of a mass media campaign on bed net use in Cameroon. Malar J. 2013:12:36.

237. Kimbi H, Nkesa S, Ndamukong-Nyanga J, Sumbele IU, Atashili J, Atanga MB. Socio-demographic factors influencing the ownership and utilization of insecticide-treated bed nets among malaria vulnerable groups in the Buea Health District, Cameroon. BMC Res Notes. 2014;7:624.

238. Fokam EB, Kindzeka GF, Ngimuh L, Dzi KTJ, Wanji S. Determination of the predictive factors of long-lasting insecticide-treated net ownership and utilisation in the Bamenda Health District of Cameroon. BMC Public Health. 2017;17:263

239. Ntonifor $\mathrm{NH}$, Veyufambom S. Assessing the effective use of mosquito nets in the prevention of malaria in some parts of Mezam division, Northwest Region Cameroon. Malar J. 2016;15:390.

240. Kwalar-Toh IG, Clinton N, Atanga MBS. Factors in association with use or non use of ITNs in rural Cameroon: case of Upper Muea. RJMMS. 2017:13:7-19.

241. Krezanoski PJ, Bangsberg DR, Tsai AC. Quantifying bias in measuring insecticide-treated bednet use: meta-analysis of self-reported vs objectively measured adherence. J Glob Health. 2018;8:010411.

242. Gonahasa S, Maiteki-Sebuguzi C, Rugnao S, Dorsey G, Opigo J, Yeka A. LLIN Evaluation in Uganda Project (LLINEUP): factors associated with ownership and use of long-lasting insecticidal nets in Uganda: a crosssectional survey of 48 districts. Malar J. 2018;17:421.

243. Etang J, Vicente J, Nwane P, Chouaibou M, Morlais I, Do Rosario V. Polymorphism of intron-1 in the voltage-gated sodium channel gene of Anopheles gambiae ss populations from Cameroon with 
emphasis on insecticide knockdown resistance mutations. Mol Ecol. 2009;18:3076-86.

244. Etang J, Manga L, Chandre F, Guillet P, Fondjo E, Mimpfoundi R. Insecticide susceptibility status of Anopheles gambiae s.l. (Diptera: Culicidae) in the Republic of Cameroon. J Med Entomol. 2003:40:491-7.

245. Etang J, Fondjo E, Chandre F, Brengues C, Nwane P, Chouaubou M. First report of knockdown mutations in the malaria vector Anopheles gambiae from Cameroon. Am J Trop Med Hyg. 2006;74:795-7.

246. Nwane P, Etang J, Chouaibou M, Toto J, Kerah-Hinzoumbe C, Mimpfoundi R. Trends in DDT and pyrethroid resistance in Anopheles gambiae s.s. Populations from urban and agro-industrial settings in southern Cameroon. BMC Infect Dis. 2009;9:163.

247. Etang J, Pennetier C, Piameu M, Bouraima A, Chandre F, AwonoAmbene P. When intensity of deltamethrin resistance in Anopheles gambiae (s.l.) leads to loss of long lasting insecticidal nets bio-efficacy: a case study in north Cameroon. Parasit Vectors. 2016;9:132.

248. Etang J, Nwane P, Piameu M, Manga B, Souop D, Awono-Ambene P. Evaluation of new tools for malaria vector control in Cameroon: focus on long lasting insecticidal nets. PLoS ONE. 2013;8:e74929.

249. Fossog Tene B, Poupardin R, Costantini C, Awono-Ambene P, Wondji CS, Ranson H. Resistance to DDT in an urban setting: common mechanisms implicated in both $\mathrm{M}$ and $\mathrm{S}$ forms of Anopheles gambiae in the City of Yaoundé, Cameroon. PLoS ONE. 2013;8:e61408.

250. Antonio-Nkondjio C, Poupardin R, Tene BF, Kopya E, Costantini C, Awono-Ambene P. Investigation of mechanisms of bendiocarb resistance in Anopheles gambiae populations from the city of Yaoundé, Cameroon. Malar J. 2016;15:424.

251. Mandeng SE, Awono-Ambene HP, Bigoga JD, Ekoko WE, Binyang J, Piameu M, et al. Spatial and temporal development of deltamethrin resistance in malaria vectors of the Anopheles gambiae complex from North Cameroon. PLoS ONE. 2019;14:e0212024.

252. WHO. Global plan for insecticide resistance management in malaria vectors (GPIRM). Geneva: World Health Organization; 2012.

253. Bamou R, Sonhafouo-Chiana N, Mavridis K, Tchuinkam T, Wondji CS, Vontas J, Antonio-Nkondjio C. Status of insecticide resistance and its mechanisms in Anopheles gambiae and Anopheles coluzzii populations from forest settings in south Cameroon. Genes. 2019;10:741.

254. Tchouakui M, Riveron JM, Djonabaye D, Tchapga W, Irving H, Takam PS, et al. Fitness costs of the glutathione S-transferase Epsilon 2 (L119FGSTe2) mediated metabolic resistance to insecticides in the major African malaria vector Anopheles funestus. Genes. 2018;9:645.

255. Dobaño C, Ubillos I, Jairoce C, Gyan B, Vidal M, Jiménez A, et al. RTS, S/AS01E immunization increases antibody responses to vaccineunrelated Plasmodium falciparum antigens associated with protection against clinical malaria in African children: a case-control study. BMC Med. 2019;17:1-19.

256. World Health Organization. Malaria vaccine: WHO position paper, January 2016-recommendations. Vaccine. 2018;36:3576-7.

257. Bhatt S, Weiss DJ, Cameron E, Bisanzio D, Mappin B, Dalrymple UJN, et al. The effect of malaria control on Plasmodium falciparum in Africa between 2000 and 2015. Nature. 2015;526:207-11.

258. WHO. World malaria report 2017. Geneva: World Health Organisation; 2017.

\section{Publisher's Note}

Springer Nature remains neutral with regard to jurisdictional claims in published maps and institutional affiliations.
Ready to submit your research? Choose BMC and benefit from:

- fast, convenient online submission

- thorough peer review by experienced researchers in your field

- rapid publication on acceptance

- support for research data, including large and complex data types

- gold Open Access which fosters wider collaboration and increased citations

- maximum visibility for your research: over 100M website views per year

At BMC, research is always in progress.

Learn more biomedcentral.com/submissions 